OPEN ACCESS

Edited by:

Tania Fiaschi,

University of Florence, Italy

Reviewed by:

W. Timothy Garvey,

University of Alabama at Birmingham

United States

Alberto Camacho-Morales, Universidad Autónoma de Nuevo

León, Mexico

${ }^{*}$ Correspondence:

Ying Liu

liuying@icarbonx.com

Gary Sweeney

gsweeney@yorku.ca

Specialty section

This article was submitted to

Translational Endocrinology,

a section of the journal

Frontiers in Endocrinology

Received: 29 June 2019 Accepted: 19 November 2019 Published: 11 December 2019

Citation:

Liu Y, Vu V and Sweeney G (2019) Examining the Potential of Developing and Implementing Use of Adiponectin-Targeted Therapeutics for

Metabolic and Cardiovascular

Diseases. Front. Endocrinol. 10:842. doi: 10.3389/fendo.2019.00842

\section{Examining the Potential of} Developing and Implementing Use of Adiponectin-Targeted Therapeutics for Metabolic and Cardiovascular Diseases

\author{
Ying Liu ${ }^{1 *}$, Vivian $\mathrm{Vu}^{2}$ and Gary Sweeney ${ }^{2 *}$ \\ ${ }^{1}$ Metabolic Disease Research Division, iCarbonX Co. Ltd., Shenzhen, China, ${ }^{2}$ Department of Biology, York University, \\ Toronto, ON, Canada
}

Cardiometabolic diseases encompass those affecting the heart and vasculature as well as other metabolic problems, such as insulin resistance, diabetes, and non-alcoholic fatty liver disease. These diseases tend to have common risk factors, one of which is impaired adiponectin action. This may be due to reduced bioavailability of the hormone or resistance to its effects on target tissues. A strong negative correlation between adiponectin levels and cardiometabolic diseases has been well-documented and research shown that adiponectin has cardioprotective, insulin sensitizing and direct beneficial metabolic effects. Thus, therapeutic approaches to enhance adiponectin action are widely considered to be desirable. The complexity of adiponectin structure and function has so far made progress in this area less than ideal. In this article we will review the effects and mechanism of action of adiponectin on cardiometabolic tissues, identify scenarios where enhancing adiponectin action would be of clinical value and finally discuss approaches via which this can be achieved.

Keywords: adiponectin, therapeutic, small molecule, peptide, precision medicine

Adiponectin, one of the most abundant circulating hormones in healthy individuals, exerts many beneficial effects on cardiometabolic health. Adiponectin functions through multiple signaling pathways that stimulate beneficial effects on metabolism, inflammation, atherosclerosis, and cardioprotective responses. Circulating levels of adiponectin decline under conditions of metabolic stress, including obesity and metabolic syndrome, and are associated with decreased adiponectin signaling. Thus, strategies that enhance or restore adiponectin action are currently being investigated as therapeutic approaches in the treatment of cardiometabolic disease.

\section{STRUCTURAL FEATURES OF ADIPONECTIN}

Circulating adiponectin is primarily derived from adipose tissue, with lower-level expression detected in several other peripheral tissues (1-4). Adiponectin monomers are oligomerized within adipocytes prior to secretion and circulate as low molecular weight (LMW) medium (MMW) and high molecular weight (HMW) forms. Extensive post-translational modifications play a critical role in adiponectin forming these oligomeric complexes. In particular, the disulfide bond formed via Cys39 (human)/Cys36 (mouse) and the hydroxylation, 
glycosylation occurred on lysine residues (lys68, lys71, lys80, lys104) are essential for adiponectin to form the hexameric and oligomeric complexes, respectively $(5,6)$. The full-length adiponectin (fAd) oligomers can be cleaved by neutrophil elastase to liberate the carboxy-terminal globular domain (gAd) which itself possesses physiological activity $(7,8)$.

\section{ADIPONECTIN RECEPTORS AND SIGNALING}

Adiponectin action is mediated primarily through adiponectin receptors 1 (AdipoR1) and 2 (AdipoR2), which are nonG-protein-coupled receptors containing seven transmembrane domains, but with an internal $\mathrm{N}$-terminus and external Cterminus (9). Both adiponectin receptors are rather ubiquitously expressed although some variations do occur, such as more abundant AdipoR1 expression in skeletal muscle and higher AdipoR2 expression in liver $(9,10)$. In vitro experiments in C2C12 myocytes utilizing siRNA demonstrated that suppression of AdipoR1 reduced gAd binding while AdipoR2 suppression primarily reduced fAd binding, and their respective downstream signaling and functional effects (9). The functional roles of adiponectin receptors have been examined in transgenic or knockout mouse models of AdipoR overexpression created by different research groups. Yamauchi et al. reported undetectable levels of adiponectin specific binding and action in AdipoR 1 and 2 double-knockout mice leading to glucose intolerance and insulin resistance in these animals. Both AdipoR1-null and AdipoR2-null mice exhibited similar phenotypes with both strains showing increased adiposity and insulin resistance (11). A consistent phenotype of insulin resistance was observed in AdipoR1 deficient mice $(12,13)$, however studies in which AdipoR2 was deleted have reported opposing phenotypes in terms of glucose tolerance and susceptibility to diet-induced insulin resistance (11-14).

Adiponectin binding to AdipoRs initiates a cascade of downstream signaling through the interaction of AdipoR to intracellular adaptor proteins (15) with APPL1 (adaptor protein containing pleckstrin homology domain, phosphotyrosine binding domain, and leucine zipper motif 1) acting as the primary adaptor protein mediating the metabolic effects of adiponectin (16). Adiponectin stimulation results in the binding of APPL1 to the cytoplasmic domain of AdipoR1 and AdipoR2 via the phosphotyrosine binding (PTB) and coiled coil (CC) domain of APPL1 (17). Subsequent translocation of LKB1 to the cytosol as well as calcium release from the endoplasmic reticulum through phospholipase $\mathrm{C}$ activates calcium/calmodulin-dependent protein kinase $(13,18,19)$. AMPK activation is the central mechanism whereby adiponectin stimulates metabolic effects $(6,7,10,13,17,18,20-26)$, induces NO-dependent vasodilation, inhibits the production of reactive oxygen species (ROS), and modulates mTOR signaling. In addition to AMPK activation, several AMPK-independent pathways exists whereby adiponectin is able to regulate insulin sensitivity, inflammation, glucose uptake, and ceramidase activity (27).

\section{PHYSIOLOGICAL EFFECTS OF ADIPONECTIN AND IMPLICATIONS IN CARDIOMETABOLIC DISEASE}

The diverse physiological functions of adiponectin in metabolic and cardiovascular tissues has significant implications in health and disease states. Multiple studies have established primarily beneficial effects of adiponectin on the regulation of metabolism, immunity, inflammation, cardiac remodeling, vasculature control and cancer $(16,28-30)$. The anti-diabetic actions of adiponectin include insulin sensitizing and insulin mimetic actions in liver and skeletal muscle, as well as protection against beta cell destruction in the pancreas (31). In addition to this, increased glucose transport and GLUT4 translocation by adiponectin in skeletal muscle is regulated by AMPK or p38 MAPK activation (17). Adiponectin increases fatty acid oxidation through PPAR $\alpha$ enhanced expression of target genes in the liver $(20,22,23)$ or through increased mitochondria biogenesis in skeletal muscle (13).

The cardioprotective effects of adiponectin can be attributed in part to effects on cardiac metabolism, apoptosis, autophagy and hypertrophy (32). Additional cardioprotection is mediated by the anti-inflammatory, antioxidant, and vasorelexant properties of adiponectin as well as its ability to inhibit atherogenesis (31). Initial in vivo studies examining the effect of adiponectin on atherosclerosis demonstrated that adenovirusmediated overexpression of adiponectin (33) and gAd treatment (23) in apolipoprotein (apo) E-deficient mice resulted in reduced atherosclerosis. Systematic review and meta-analysis of human clinical trials suggests an important role of adiponectin in the development of atherosclerosis, as hypoadiponectinemia was associated with early carotid artery atherosclerosis lesions in healthy and metabolic disease populations (34). It should be noted that this association was weak (34) and not consistent across all studies (35) but in vitro experiments as well as animals studies have reported data supporting the anti-atherogenic properties of adiponectin. Adiponectin inhibits multiple steps involved in the development of atherosclerotic lesions including the reduction of macrophage lipid accumulation, inhibition of macrophage to foam cell formation, suppression of proinflammatory cytokines release and lymphocyte migration, inhibition of leukocyte and endothelial cell interaction, and suppression of vascular smooth muscle proliferation through the inhibition of atherogenic growth factors $(31,36)$. In the early development of atherosclerosis, adiponectin has been demonstrated to inhibit monocyte-macrophage migration, thus reducing the attachment of monocytes to injured endothelial cells and the formation of macrophage foam cells $(37,38)$. In addition to this, adiponectin can downregulation scavenger receptor A (SR-A) and acyl-coenzyme A: cholesterol-acyltransferase 1 (ACAT1) expression, both of which are important regulators of macrophage lipid accumulation and foam cell formation $(39,40)$ Adiponectin can also inhibit foam cell formation by modulating lipid metabolism and cholesterol efflux in macrophages $(41,42)$ and altering the activity of enzymes (i.e., heptaic lipase, lipoprotein lipase) involved in the catabolism of lipoproteins 
(41). The effects of adiponectin on foam cell formation is mediated through an adiponectin-AdipoR1/2-APPL1 axis in macrophages $(43,44)$. Thus, adiponectin is a critical factor regulating the development of atherosclerosis which accounts for its beneficial effects on cardiometabolic diseases.

Dysregulation of cardiac energy metabolism is an important feature seen in early stages of heart failure. Cardiomyocyte contractile energy in the healthy heart under aerobic conditions is derived from fatty acids $(\sim 70 \%)$ and glucose $(\sim 30 \%)$ and this balance is perturbed under conditions of cardiac stress, such as under ischemic conditions (45). Our group (4648) and others (49-51) have shown that adiponectin can regulate cardiac energy metabolism. Both globular and fulllength adiponectin stimulation led to increased glucose uptake and metabolism (46) via the activation of AMPK, IRS1, and Akt1 in primary neonatal rat cardiomyocytes. The effect of adiponectin on cardiomyocyte glucose uptake is dependent on Rho/ROCK regulated actin cytoskeleton remodeling which colocalized APPL1 to actin filaments (48). Similar results were observed in primary adult rat cardiomyocytes with adiponectin significantly enhancing insulin stimulated Akt phosphorylation and glucose uptake (47). The effect of lipotoxicity on cardiac insulin signaling was examined in adiponectin knockout mice and a significant reduction in insulin stimulated Akt signaling was observed in high fat fed mice compared to chow fed group and adiponectin replenishment was able to reverse the defect in insulin signaling (52). Adiponectin treatment increased the expression of fatty acid transporter protein-1 and induced the translocation of CD36 to the outer cell membrane in primary neonatal and adult rat cardiomyocytes, respectively, resulting in increased fatty acid uptake $(47,48)$. Adiponectin, via AdipoR1APPL1 signaling, regulates fatty acid $\beta$-oxidation in primary rat cardiomyocytes and isolated working heart through the activation of AMPK leading to acetyl coenzyme A carboxylase (ACC) phosphorylation and enhanced fatty acid oxidation (47, 48). These results suggest that adiponectin isoforms regulate cardiac metabolism and function leading to more efficient utilization of glucose and fatty acids.

Adiponectin attenuates cardiomyocyte apoptosis seen in heart failure through several different signaling pathways. Adiponectin treatment was protective against stress-induced apoptosis through Akt-dependent signaling (53) in HL-1 cardiomyocytes. In cultured $\mathrm{H} 9 \mathrm{c} 2$ cells and adiponectin-null mice, globular adiponectin attenuated hypoxia/reoxygenationinduced apoptosis through the reduction of reactive oxygen species $(54,55)$. Adiponectin stimulation of ceramidase activity plays a vital role in cell survival through ceramide degradation and production of sphingosine 1-phosphate (S1P) both of which protected primary mice neonatal ventricular cardiomyocytes from palmate-induced apoptosis (56). Our group has recently demonstrated the importance of ceramidase activity in the cardioprotective effects against reactive oxygen species (ROS) and apoptosis. High fat diet (HFD) in adiponectin knockout mice increased myocardial total triglyceride, ceramides, and sphingosine-1-phosphate (S1P) compared to chow-fed animals with adiponectin replenishment resulting in significant reduction in S1P intracellular content. When these conditions were simulated in an in vitro model of lipotoxicity, palmitate treatment significantly increased S1P intracellular concentrations in $\mathrm{H} 9 \mathrm{c} 2$ cells. Addition of a synthetic adiponectin receptor agonist, AdipoRon, to palmitate-treated $\mathrm{H} 9 \mathrm{c} 2$ cells reduced intracellular concentrations while simultaneously increasing secretion of S1P which was consistent with attenuation of palmitate-induced ROS production and cell death. Thus, in vivo and in vitro results suggests that through the activation of cardiac ceramidase activity, adiponectin increases the conversion of ceramide to S1P which is secreted to exert autocrine/paracrine cardioprotective effects (52).

Regulation of cardiomyocyte autophagy is now recognized as an important mechanistic component of the cardioprotective effects of adiponectin. Examination of myocardial autophagy in an in vivo animal model of oxidative stress induced by chronic angiotensin II (Ang-II) treatment showed increased LC3II protein expression in the left ventricle which was significantly higher in adiponectin knockout vs. wild-type mice (57), this most likely resulting from a block of autophagic flux. $\mathrm{H}_{2} \mathrm{O}_{2}$ induced autophagic cell death in isolated adult rat ventricular myocytes through AMPK/ERK activation, mTOR inhibition, and increased expression of authophagic protein. This led to autophagasome accumulation and adiponectin pre-treatment ameliorated the effect of oxidative stress on autophagy (57). Cardiac autophagy is a dynamic process which is activated in response to stress but can become inhibited in chronic pathological conditions. In studies examining the effect of HFD on autophagy in wild-type and adiponectin knockout mice, a compensatory elevation in autophagy in response to HFD was lacking in Ad-KO mice (58). Aortic banding to induce pressure overload cardiac dysfunction resulted in activation of cardiac autophagy in wild-type mice but this change was deficient in adiponectin-null mice (59). Inhibited autophagy was also observed in adiponectin knockout mice following lipopolysaccharide challenge compared to wild-type mice which had upregulated LPS-induced autophagy through AMPK-mTOR-ULK1 dependent signaling (60). In vitro studies with $\mathrm{H} 9 \mathrm{c} 2$ cells, revealed an important role of adiponectin in the stimulation of autophagy flux in cardiomyocytes at multiple steps within the autophagy pathway (59). In adiponectin deficient mice, the normal autophagic response of cardiomyocytes to stressors is inhibited and in vitro data suggests that adiponectin replenishment can correct this abnormal response. Collectively, in vitro and in vivo animal studies provide convincing evidence of multiple mechanisms in which adiponectin can enhance cell survival and metabolism through the regulation of autophagy.

Cardiac hypertrophy can be a normal physiological response which occurs secondary to pressure overload, however under specific circumstances hypertrophy can become pathological and lead to cardiac dysfunction (32). Adiponectin has been demonstrated to protect against pathological cardiac hypertrophy in both in vitro and in vivo experiments. Multiple studies have reported exaggerated pathological cardiac hypertrophy in adiponectin knockout mice under experiment models of pressure overload (6163) with adiponectin replenishment resulting in reduced pathologic hypertrophy (62). Experiments in isolated neonatal 
rat ventricular myocytes treated with angiotensin II to induce hypertrophy illustrated that the primary anti-hypertrophic mechanism of adiponectin occurred through AdipoR1-APPL1AMPK activation resulting in suppression of nuclear factor kappa-B-induced hypertrophic growth signaling (64-66). These studies suggest that adiponectin can protect against cardiac hypertrophy and lack of adiponectin can lead to development of more severe pathological hypertrophy. In summary, evidence to date illustrates that the cardioprotective effects of adiponectin are mediated through effects on multiple cell types (e.g., endothelial cells, vascular smooth muscle cells, cardiomyocytes, fibroblasts, macrophages) involved in cardiac metabolism, survival and remodeling.

\section{THE ROLE OF ADIPONECTIN AS A BIOMARKER}

Adiponectin circulates at high concentrations in humans and rodents (67) and hypoadiponectinemia is associated with metabolic syndrome across different ethnic groups (34, 6870). Adiponectin levels in humans are inversely related to BMI and fat mass with reduced adiponectin mRNA expression, HMW adiponectin secretion and total serum levels observed in obesity, insulin resistance, T2DM, CVD, and metabolic syndrome $(34,68,71-73)$. Human studies have reported an inverse correlation between adiponectin levels and the risk of cardiovascular morbidity and mortality. Hypoadiponectinemia has been associated with early carotid artery atherosclerosis lesions in humans $(34,74)$, while higher serum adiponectin levels are correlated with favorable cardiovascular risk profiles in both males and females $(75,76)$. Higher adiponectin levels were also associated with a reduced risk of developing type 2 diabetes and the subsequent risk of cardiovascular events in a large population of healthy patients (77). Consistent with these cardioprotective effects are studies demonstrating an association between persistent hypoadiponectinemia following acute myocardial infarct with increased risk of future major adverse cardiovascular events $(78,79)$. In contrast, multiple studies have reported increased adiponectin levels in patients with advanced cardiovascular disease. In a prospective study of men and women without initial diagnosis ischemic heart disease or HF, higher adiponectin levels was directly correlated with increased risk of heart failure (80). The EXAMINE trial found a direct relationship between adverse cardiovascular outcomes and higher adiponectin levels in type 2 diabetic patients with recent acute coronary syndrome (81). In patients with chronic heart failure, high adiponectin levels were associated with an increased risk of mortality (82). Clinical studies in older populations demonstrated a positive association between adiponectin levels and mortality in patients with heart failure (83, 84). The paradoxical association of adiponectin levels in relation to cardiovascular disease was further illustrated by observations from the Copenhagen City Heart Study which reported a positive relationship between high adiponectin and decreased risk factors for CVD in patients without initial CVD disease. This same study also found a positive direct correlation between adiponectin levels and all-cause mortality and major adverse cardiovascular events (76).

This adiponectin paradox has been proposed to occur secondary to adiponectin resistance, a hypercatabolic state or in response to elevated natriuretic peptides which are found in advanced CVD. In particular, both human and animal studies have suggested that adiponectin resistance as a consequence of AdipoR1 downregulation may be present in severe CVD and thus hyperadiponectinemia is a compensatory mechanism $(85,86)$. The wasting theory proposes that the hypercatabolic state in severe heart failure leads to increased adiponectin which is consistent with the inverse relationship between adiponectin and fat mass (87). Supporting this theory are observations showing hyperadiponectinemia only in the presence of cachexia in heart failure patients (88). Cardiac natriuretic peptides, atrial natriuretic peptide (ANP) and brain natriuretic peptide (BNP), are important mediators in the crosstalk between heart and adipose tissue. This was demonstrated in transgenic mice models where whole body as well as adipose tissue specific deletion of the NP clearance receptors, resulting in enhanced ANP action, protected mice from diet induced obesity and insulin resistance (89). In human cultured adipocytes, ANP stimulated lipolysis (90) and promoted the "browning" of white adipose tissue through enhanced energy expenditure via upregulation of mitochondrial biogenesis, respiration and UCP1 expression (91). Unpublished data from our group suggest that defective cardiac autophagy leads to reduced ANP-mediated inter-organ crosstalk leading to impaired glycemic control. Increased natriuretic peptides release is an indicator of cardiac stress and is used as a clinical biomarker of heart failure. Both ANP and BNP were found to enhance the expression of adiponectin mRNA and secretion from primary human adipocytes (92). This observation was reproducible in human studies with infusion of ANP resulting in increased total and HMW adiponectin concentrations in healthy men (93) and patients with chronic heart failure (92). Clinical studies have also provided evidence for a positive, independent association between adiponectin levels and BNP in healthy subjects (94) and in men with ischemic heart disease (95). Concomitantly elevated proBNP was associated with elevated adiponectin levels observed in patients who developed heart failure in an 8.5 years follow-up prospective study of subjects without initial diagnosis of heart disease (80). Thus, both ex vivo and in vivo analyses have provided evidence supporting the idea that hyperadiponectinemia in advanced CVD can be driven by elevated natriuretic peptides.

Overall, the clinical value of adiponectin as a biomarker remains highly promising, especially for metabolic and cardiovascular diseases $(96,97)$. However, published findings suggest that clinical interpretation of circulating adiponectin levels must be done in the context of factors, such as age, gender, and severity or stage of CVD $(98,99)$.

\section{ADIPONECTIN AS A BIOTARGET}

Research studies to date have proven the significant potential of adiponectin as a biotarget for the modulation of metabolic and 
cardiovascular disease. However, the exogenous administration of recombinant adiponectin has proven to be difficult due to the challenges associated with producing stable multimeric recombinant adiponectin isoforms. Further complicating the process of establishing a therapeutic dose is the high endogenous concentration and the relative short in vivo half-life of adiponectin $(100,101)$. The therapeutic success of adiponectin thus lies in approaches aimed at enhancing endogenous levels of expression as well as strategies to target adiponectin signaling and its downstream effector pathways.

\section{CURRENT KNOWLEDGE AND FUTURE APPROACHES FOR HOW ADIPONECTIN CAN BE TARGETED THERAPEUTICALLY}

\section{Increase Circulating or Local Levels}

As summarized in Figure 1, overcoming the reduction in circulating adiponectin levels observed in disease states, such as obesity and diabetes has potential to be beneficial. Lifestyle interventions are an effective strategy to increase circulating adiponectin levels. Interventions, such as exercise, caloric restriction, pharmacological drugs, or gastric bypass leading to weight loss have consistently shown a positive effect on adiponectin levels. Weight loss induced by a combination of lifestyle and pharmacological (phentermine/topiramate) interventions resulted in an increase in adiponectin levels in patients with metabolic syndrome $(102,103)$. Circulating adiponectin levels significantly increased following gastric bypass and sleeve gastrectomy in obese women and this was negatively correlated with body weight and waist circumference (104). Both gastric bypass and very low calorie diets led to improved adiponectin levels in obese type 2 diabetic subjects (105). Exercise training leading to weight loss in overweight, obese and diabetic subjects was associated with increased adiponectin levels (106-109). These findings support the idea that sustained weight reductions through lifestyle modifications can enhance adiponectin levels.

Thiazolidinediones (TZD), prescribed for the treatment of diabetes, are perhaps the most extensively characterized regulator of adiponectin expression. TZDs, such as pioglitazone and rosiglitazone increase adiponectin expression through the activation of proliferator-activated receptor gamma (PPAR $\gamma$ ) $(110,111)$. Pioglitazone treatment for 16-weeks increased adiponectin levels in an obese population of Chinese subjects with diabetes and this correlated with improved insulin secretion and insulin sensitivity (112). Clinical studies in subjects across different ethnic, age and metabolic disease groups have consistently observed increased adiponectin levels with pioglitazone (113-115) or rosiglitazone (116) treatment. Importantly, TZDs up-regulate both total expression and HMW oligomers content in both in vitro as well as in vivo animal and human studies $(3,117,118)$. However, the adverse side effects which have unfortunately blighted use of TZDs $(119,120)$ limit their utility as a go-to agent to increase adiponectin levels.

Specific dietary supplements have been recognized as regulators of adiponectin expression. Evidence from in vitro and in vivo studies suggests that vitamin E can upregulate adiponectin

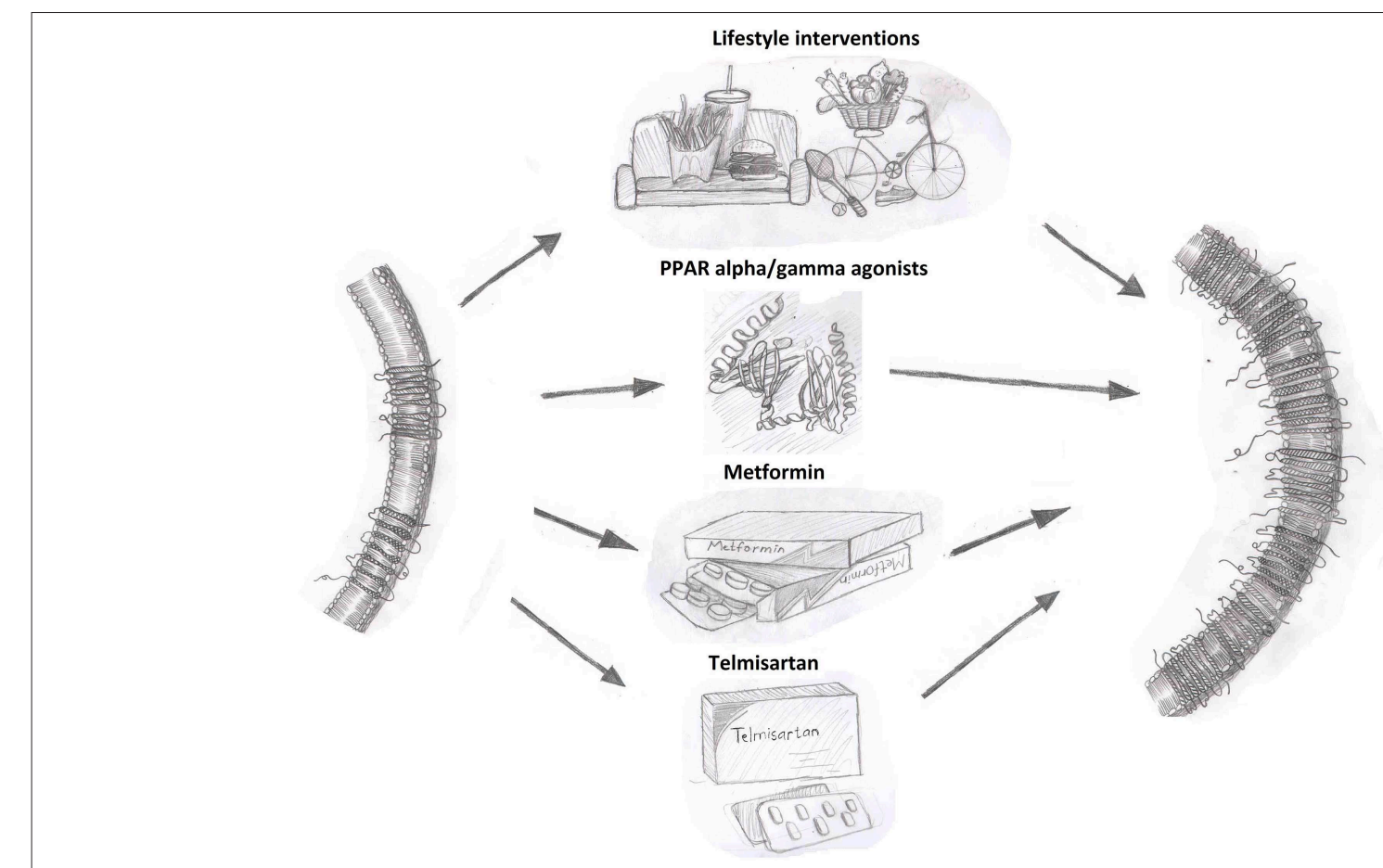

FIGURE 1 | Interventions that enhance adiponectin receptor expression. Adiponectin receptor expression can be increased by lifestyle interventions, such as diet and exercise as well as through pharmacological therapies as shown. 
expression, also through the activation of PPAR $\gamma$. Treatment with $\gamma$ - and $\alpha$-tocopherol, vitamers of vitamin E, enhanced adiponectin expression in 3T3-L1 adipocytes and mice (121) and was able to ameliorate the suppressive effects of TNF- $\alpha$ on adiponectin expression in 3T3-L1 adipocytes (122). Both fish oil (123) and omega-3 $(124,125)$ supplementation increased adiponectin levels in human studies. St. John's Wort (Hypericum perforatum) (126) and Groundsel Bush (Baccharis halimifolia) extract (127) induce 3T3-L1 adipocyte differentiation leading to enhanced adiponectin expression. Additional supplements that have been shown to increase circulating adiponectin in humans and animals include grape-seed extract (128-130) green tea extract $(131,132)$, walnuts $(133,134), \alpha$-linolenic acid (135), resveratrol (136-138), and Radix Astragali isolated compounds (astragaloside II and isoastragaloside I) (139).

Targeting the renin-angiotensin aldosterone system through angiotensin-converting enzyme inhibitor (ACEi) and angiotensin receptor blockers (ARBs) have consistently increased adiponectin levels in humans through PPAR $\gamma$ activated adiponectin gene transcription and enhanced adipogenesis (140). The ACEi inhibitor temocapril also significantly increased adiponectin expression in patients with essential hypertension (141). Ex vivo experiments with human omental (OM) preadipocytes from healthy women showed significantly higher adiponectin mRNA expression in adipocytes differentiated in the presence of ARBs vs. TZDs (140). Finally, it was suggested that enhanced adiponectin expression was specific to PPAR $\gamma$ ligand ARBs (e.g., irbesartan, telmisartan) via studies in 3T3-L1 adipocytes and ex vivo epididymal fat from Zucker $\mathrm{fa} / \mathrm{fa}$ rats $(142)$.

Incretins [e.g., glucagon-like peptide 1 (GLP-1), GLP-1 analogs (e.g. liraglutide)] and pharmacological agents used to increase incretin bioavailability [e.g., dipeptidyldipeptidase 4 (DPP4) inhibitors] upregulate adiponectin expression in 3T3-L1 adipocytes (143) as well as in clinical trials (144). Evidence from systematic review and meta-analysis of randomized controlled trials suggests that statins can increase adiponectin concentrations despite its negative effect on insulin sensitivity (145) and risk for developing diabetes mellitus (146). Empagliflozin, a diabetes pharmacological agent that works through the inhibition of sodium-glucose cotransporter-2, was been reported to increase adiponectin levels in mice through an unknown mechanism $(147,148)$. Together, these studies suggest that multiple pathways can regulate circulating adiponectin expression either through direct stimulation of gene expression or through mechanisms that enhance adipogenesis and insulin sensitivity.

\section{Alter Level (or Localization) of Adiponectin Receptors or Signaling Pathway Proteins}

Regulation of AdipoR expression and downstream signaling effector proteins are clearly prime candidates which have been targeted to enhance adiponectin action and several compounds have been identified as possible regulators of adiponectin receptor expression. PPAR agonists have been reported to enhance AdipoR expression in various cell types. In epididymal white adipose tissue (WAT) of male KKAy mice, AdipoR1 and AdipoR2 expression was upregulated following treatment with the PPAR $\alpha$ agonist Wy-14,643 (149). AdipoR2 but not AdipoR1 mRNA expression was increased by PPAR $\alpha$ and PPAR $\gamma$ agonist in primary human and THP-1 macrophages (150). Rosiglitazone increased both AdipoR1 and AdipoR2 mRNA in isolated adult rat ventricular cardiomyocytes (51). In humans, pioglitazone treatment increased both AdipoR1 and AdipoR2 mRNA in muscle biopsies from type 2 diabetic subjects (151). Telmisartan, an ARB with selective PPAR $\gamma$ activity, was observed to correct the reduced ventricular cardiomyocytes AdipoR2 and aortic AdipoR1 in diabetic rat to comparable levels as control animals (152). Metformin, a first-line pharmacotherapy for treatment of diabetes, is a potent activator of AMPK with insulin sensitizing effects. Studies in ZDF rats demonstrated that metformin can upregulate AdipoR1 and AdipoR2 receptor expression in muscle and AdipoR1 in WAT (153). In addition to effects on adiponectin levels, exercise training in animals and humans is associated with enhanced AdipoR expression (109). Studies in obese and diabetic animal models consistently report upregulation of skeletal muscle AdipoR1 expression in response to different exercise programs $(154,155)$. In humans, AdipoR1 and AdipoR2 expression in skeletal muscle increased in response to endurance exercise programs $(156,157)$. Collectively, these findings further support the benefit of lifestyle interventions in enhancing adiponectin action.

\section{Receptor Agonists-What's Available and Future Developments}

AdipoR agonists (Figure 2) have been an intense focus of pharmaceutical drug development programs in metabolic and cardiovascular diseases $(20,158)$. Ligand binding receptors are of course recognized as the logical targets for activating/inhibiting that signaling pathway. Given the difficulties in producing biologically active adiponectin and optimizing the exact dosage and route of administration for this recombinant protein, designing agonists to activate adiponectin receptor-mediated downstream signaling is a highly desirable strategy to maximize adiponectin's beneficial effects. Several small molecules or short peptides have been discovered for this purpose since Kadowaki's group identified AdipoR1 and AdipoR2 (9).

\section{ADP355/ADP399}

The C-terminal of adiponectin (residues 105-254) that forms gAd is well-established to induce potent biological effects in various studies $(21,159)$. By screening 66 small peptides overlapping each other by 10 amino acids and covering the entire sequence of the globular domain of adiponectin, Otvos et al. discovered that the peptide sequence between residues 149-166 retained biological activity similar to gAd (160). A patent was filed (US9,073,965) indicating the potential of developing this sequence into a receptor agonist. After additional pharmacological modifications and structure-function assays, a short peptide named ADP355 (H-DAsn-Ile-Pro-NvaLeu-Tyr-DSer-Phe-Ala-DSer-NH2), was formed acting as an 

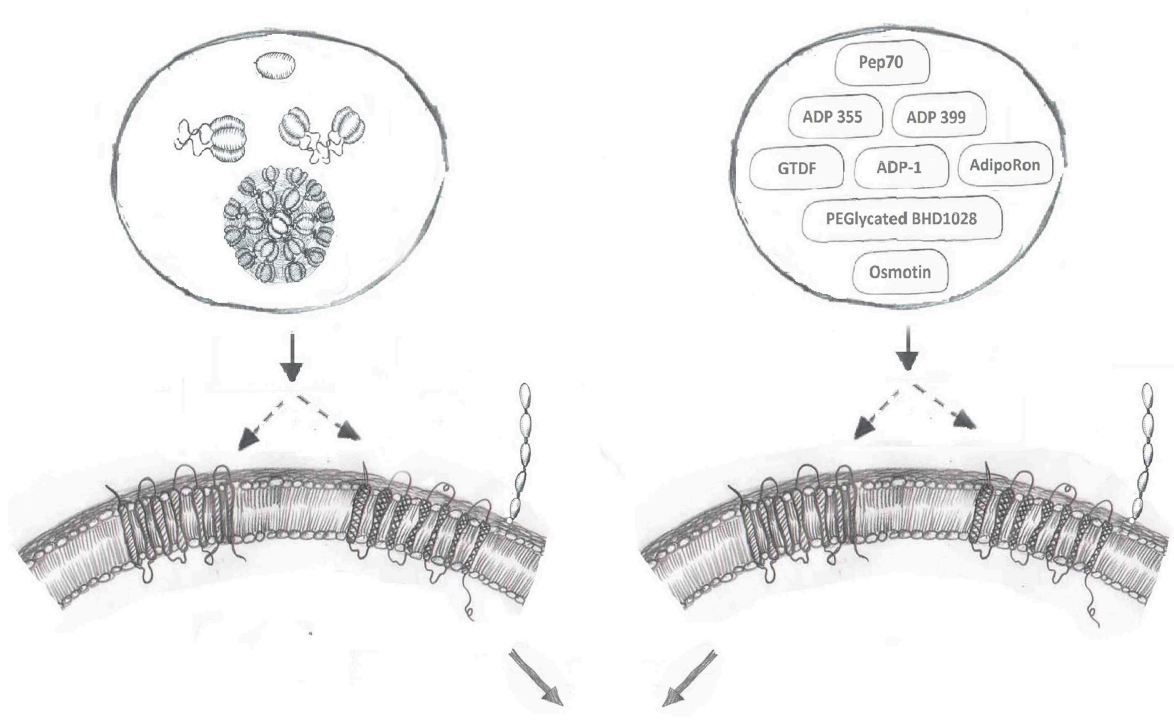

Activation of signaling pathways

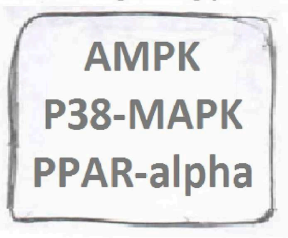

FIGURE 2 | Adiponectin receptor agonists. Binding of full-length and globular adiponectin to adiponectin receptors with seven transmembrane spanning domains (left side) normally activates downstream signaling pathways, such as AMPK, p38MAPK, and PPAR-alpha. Multiple adiponectin receptor agonists have now been identified to also bind adiponectin receptors and induce these downstream signaling cascades.

active adiponectin receptor agonist. Follow up in-vitro activity assays including cell proliferation assay and western blot to monitor the activation of key signaling molecules (AMPK, AKT, STAT3, ERK1/2 etc.) in various cancer cell lines, revealed effects of ADP355 in the concentration range $100 \mathrm{nM}-10$ uM comparable to or exceeding those of gAd (161). A bolus injection of $5-50 \mathrm{mg} / \mathrm{kg}$ ADP355 displayed excellent stability and minimum toxicity in-vivo. Furthermore, a $1 \mathrm{mg} / \mathrm{kg} / \mathrm{day}$ ADP355 treatment via intraperitoneal (i.p.) injection for 28 days significantly inhibited the growth of human breast cancer xenograft in mouse (161). With the initial success, Otvos et al. continued to explore ways to pharmacologically enhance the agonist activity of $A D P 355$. In considering adiponectin normally circulates in its multimeric forms, the second generation of the peptide, a linear branched dimer (ADP399) and an octapeptide (ADP400), was formed. The dimeric peptide ADP399 exhibits almost 20-fold increased cellular activity in comparison to the monomeric peptide ADP355. However, surprisingly, at the similar concentration, $A D P 400$ acted as an antagonist rather than an agonist to AdipoRs (160).

\section{ADIPORON}

AdipoRON, a synthetic small molecule that can be administered orally, is the most well-studied AdipoR agonist currently available. In 2013, via screening chemical library compounds provided by the Open Innovation Center for Drug Discovery in University of Tokyo, Kadowaki's group successfully identified AdipoRON as the most potent agonist for AdipoR's (162). During the screening assay, the phosphorylation of AMPK, the key targeted signaling molecule for adiponectin, was used as the readout for evaluating the activity of all chemical compounds in the screen. In $\mathrm{C} 2 \mathrm{C} 12$ myotubes, comparing to the treatment of native adiponectin protein, AdipoRON induced a comparable and dose-dependent phosphorylation of AMPK within the concentration of 5-50 uM. AdipoRON was identified as agonist for both AdipoR1 and AdipoR2. An intravenous injection of AdipoRON, in the dose of $50 \mathrm{mg} / \mathrm{kg}$, induced the phosphorylation of AMPK in both skeletal muscle and liver of wt mice, however, this phosphorylation was abolished in AdipoR1 and AdipoR2 double knockout mice (162). One key advantage of a small molecule receptor agonist in the pharma industry is oral administration. To test the therapeutic potential of AdipoRON in alleviating metabolic disorders, 50 $\mathrm{mg} /$ bodyweight of AdipoRON was given to diet induced obese mice via oral administration for 8 days. AdipoRON effectively improved insulin sensitivity and restored glucose homeostasis via the activation of AdipoR1-AMPK-PGC1 $\alpha$ and AdipoR2-PPAR $\alpha$ signaling pathways (162). AdipoRON treatment also mimicked adiponectin's established anti-diabetic effects (163) and ability 
to enhance cellular capacity for mitigating oxidative-stress $(162,164)$, enhancing lipid/glucose oxidation in mitochondria (162, 164), anti-inflammatory responses (162, 164-167), lifeprolonging effect $(162,163)$, anti-cancer effects $(168,169)$, procell survival and anti-apoptotic effect $(170,171)$, neuronal- (172, $173)$, reno- $(174,175)$, and cardio-/vascular-protective effects $(165,176-179)$. However, exciting AdipoRON research in animal models has not been translated to establishment of a drug for human use and the search continues for additional small molecule AdipoR agonists which have little or no toxicity.

\section{OSMOTIN}

Osmotin, a plant protein, that was found to be structurally similar to adiponectin, can also induce the phosphorylation of AMPK in C2C12 myotubes (180). Interestingly, the adiponectin receptor, AdipoR1, is the mammalian homolog of the osmotin receptor, PHO36 (180). Based on these observations, it was proposed that osmotin could function as an agonist for AdipoR1 (181). Indeed, an osmotin peptide with nine residues (CTQGPCGPT) was synthesized and its molecular interaction with AdipoR1 was modeled in silico. Functional analyses revealed similar biological effects, evaluated as the induction of IL- 6 production in synovial fibroblasts, of fAd $(5 \mathrm{ug} / \mathrm{ml})$ and osmotin peptide (5 ug/ml) $(181,182)$. Studies with in-vivo, in-vitro treatment of osmotin also revealed its adiponectin's memetic effect toward obesity, diabetes and related fatty liver, cardiovascular diseases (183-186). The activation of AdipoRs mediated downstream signaling pathways including AdipoRs/PPAR $\alpha$ (185) and AdipoR1/PI3K/AKT (183) upon osmotin treatment, further confirmed the agonist activity of osmotin peptide to AdipoRs, in particularly to AdipoR1 (187). Interestingly, a group of Korean scientists led by Dr. Kim MO have conducted series of studies and revealed the neuroprotective effect of osmotin, in particular to Alzheimer disease. Firstly, they shown the preventive effect of osmotin on amyloid beta-induced synaptic deficits, $A \beta$ accumulation, $\beta$-secretase expression and tau phosphorylation via reduced phosphorylation of PI3K, Akt, and GSK in mice (188). Secondly, they identified AdipoR1/TLR4/NFkB, AdipoR1/AMPK/SIRT1/SREBP2 signaling, and AdipoR1 interfered Nogo-receptor 1 (Ng1) signaling are three key pathways that responsible for osmotin diminished neuroinflammation and $\mathrm{A} \beta$ accumulation while improved neurodegenerative disease related, synaptic deficits, cognitive impairment, memory loss and long-term potentiation (189192). Lastly, an osmotin preloaded magnetic nanoparticles demonstrated a novel drug delivery approach for the treatment of Alzeimer (193).

\section{OTHERS}

Additional AdipoR activating small molecules have also been studied as potential therapeutic agents. Via an in silico approach, peptide Pep70 was identified as a potential AdipoR1 agonist in protecting against fibrosis (194). PEGylated BHD1028 was discovered and formulated for the treatment of diabetes (195).
Others identified that a short region of adiponectin protein $\mathrm{N}$ terminus $(6,15-35)$ can act as agonist to AdipoRs and activate the downstream signaling pathways to promote cell viability and proliferation, thus maintaining pancreatic beta cell mass and preventing the development of diabetes (196). Another orally active AdipoR agonist named6-C-b-D-glucopyranosyl(2S,3S)-(+)-5,7,39,49-tetrahydroxydihydroflavonol (GTDF) was identified and its biological effects characterized (197), followed by identification of a 13-amino acid residue segment located in the collagen domain of adiponectin (ADP-1) as another potent AdipoR1 agonist (198). The corresponding functional studies have revealed that GTDF can bind to both AdipoRs, with a preference for AdipoR1, and activate associated signaling pathways to improve metabolic health, including glucose uptake, lipid profile, beta cell survival, reduced steatohepatitis and the browning of adipose tissue $(197,198)$.

Many efforts have been invested in identifying and optimizing AdipoR agonists as a class of therapeutic drugs, however, none of them has reached the stage of being adopted in clinical practice yet. This may due to the interpersonal variants in endogenous adiponectin and adiponectin receptor expression levels and the complicated cross-reactive molecular networks formed around its signaling pathway. Besides, it is also important to realize that the development of adiponectin resistance in certain disease states, possibly due to the reduced expression or altered post-translational modification of adiponectin receptors or adaptor proteins, such as APPL1, could also significantly affect the effectiveness of AdipoR agonists (10, 199-201). However, with recent advances in high throughput and high content drug discovery technologies $(202,203)$ and the establishment of AdipoR crystal structure to facilitate rational drug design (204), it is possible to expect further refinement of small molecule AdipoR agonists for the treatment of metabolic and cardiovascular diseases.

\section{FUTURE CONSIDERATIONS}

\section{A Personalized Approach to Maximizing Effectiveness of Adiponectin Therapeutics}

There clearly is huge potential for implementing use of adiponectin-based therapeutics, and when the time comes we must also make progress in stratifying ways to better deploy their use. Here, we list several possible directions that could be follow to maximize health impact of future advances in adiponectinrelated drug discovery.

\section{Crosstalk With the Microbiome}

As our understanding of the bio-effects of adiponectin has developed during the last decade, so too has knowledge of the important role that gut microbiota plays in metabolic health (205). Like adiponectin, targeting microbiota has also been suggested to have therapeutic value in treating metabolic syndrome. A large number of studies in rodents and humans have now validated the concept that insulin resistance condition could be improved upon receiving a more healthy donor's intestinal microbiota via a procedure called fecal microbiota transplantation (FMT) (206). Interestingly, it was found that expression of adiponectin can also be modulated by specific 
changes in gut microbiota composition. FMT, especially of those that are enriched in Lactobacillus NK6 colony (very similar to Lactobacillus taiwanensis strain BCRC 17755) can induce adiponectin expression from gut epithelial cells (207). Indeed, it has been proposed that activation of adiponectin signaling can also mediate the beneficial physiological effects of Lactobacillus (208). The important role of gut microbiota in mediating drug absorption and metabolism has now been recognized (209). Specifically, one study identified more than five phase-I metabolites and many possible glucuronic acid conjugated phase-II metabolites generated upon AdipoR agonist AdipoRON treatment (210). However, whether these metabolites are generated from microbe or host mediated drug metabolism, and whether there is any functional significance related to those metabolites are still under investigation. Thus, future studies focused on developing adiponectin-based therapies must include considering the dynamic interaction among gut microbiota, host metabolism and adiponectin based drug metabolism (211).

\section{Artificial Intelligence (Al) Assisted Drug Development and Use}

The analysis of pharmacokinetics and pharmacodynamics on adiponectin based drug metabolism is often long and costly, yet artificial intelligence using machine learning algorithms are now able to assist this process. An example for AI assisted drug development is analysis of the hepatic toxicity effect of terbinafine, an oral antifungal agent (212). Nearly 20 years after the initial safety watch regarding its hepatic toxicity effect, a machine learning algorithm trained with large dataset of known metabolic pathways identified what no human could previously: the detailed 2-step metabolic processes that led to the breakdown of terbinafine into its toxic metabolite, TBFA $(213,214)$. Using an AI assisted computational approach could help in forming a comprehensive understanding of metabolism for new adiponectin-mimetic small molecules and thus assist in making logical predictions of potential pharmacological considerations.

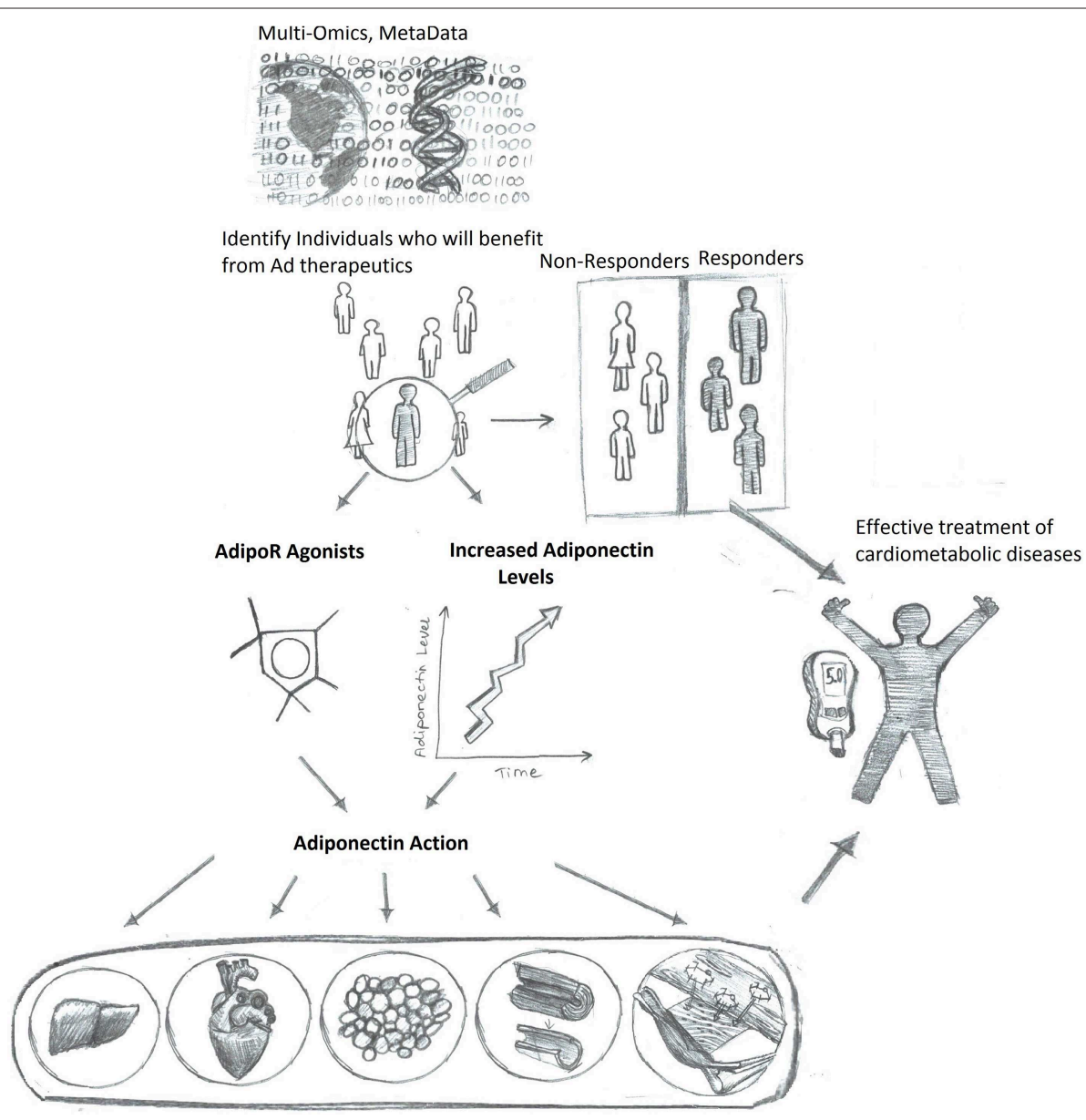

FIGURE 3 | Enhanced adiponectin therapeutics via precision medicine upon personalized response prediction. Accumulation of big data will allow algorithm-based prediction of those individuals most likely to benefit from therapeutic agents to either increase adiponectin levels or directly mimic adiponectin action, thus resulting in more efficient and improved health care outcomes. 


\section{Precision Medicine to Maximize Impact of Adiponectin-Based Therapeutics}

Interpersonal variants in factors including the expression level of adiponectin and adiponectin receptors, the largely diverse life style (such as food composition, exercise frequency, sleep quality), the stage at which individuals are located along the course of disease progression, ultimately determine the individualized response to potential therapeutic interventions (215-218). The reciprocal interplay between microbiota and adiponectin action has also created personal variables in drug efficiency (208). All the above listed factors played important role on the yet not so successful translational trials on adiponectin based drug development. In order to design the most effective treatment plan according to all such variants, the concept of precision medicine is important. Several pioneering studies have illustrated the power of personalized profiling in understanding and capturing individualized characterization under the same clinical phenotype (219-221). For example, unique groups of small molecules were identified as being characteristic for each individual and that they differed from the group mean. These individualized datasets can serve as early predictive signatures for disease warning and allow specific preventive treatments to be planned accordingly in order to delay the occurrence of

\section{REFERENCES}

1. Scherer PE, Williams S, Fogliano M, Baldini G, Lodish HF. A novel serum protein similar to C1q, produced exclusively in adipocytes. J Biol Chem. (1995) 270:26746-9. doi: 10.1074/jbc.270.45.26746

2. Maeda K, Okubo K, Shimomura I, Funahashi T, Matsuzawa Y, Matsubara K. cDNA cloning and expression of a novel adipose specific collagen-like factor, apM1 (AdiPose Most abundant Gene transcript 1). Biochem Biophys Res Commun. (1996) 221:286-9. doi: 10.1006/bbrc.1996. 0587

3. Liu Y, Chewchuk S, Lavigne C, Brule S, Pilon G, Houde V, et al. Functional significance of skeletal muscle adiponectin production, changes in animal models of obesity and diabetes, and regulation by rosiglitazone treatment. Am J Physiol Endocrinol Metab. (2009) 297:E657-64. doi: 10.1152/ajpendo.00186.2009

4. Achari AE, Jain SK. Adiponectin, a therapeutic target for obesity, diabetes, and endothelial dysfunction. Int J Mol Sci. (2017) 18:E1321. doi: 10.3390/ijms18061321

5. Wang Y, Xu A, Knight C, Xu LY, Cooper GJ. Hydroxylation and glycosylation of the four conserved lysine residues in the collagenous domain of adiponectin. Potential role in the modulation of its insulin-sensitizing activity. J Biol Chem. (2002) 277:19521-9. doi: 10.1074/jbc.M200601200

6. Tsao TS, Tomas E, Murrey HE, Hug C, Lee DH, Ruderman NB, et al. Role of disulfide bonds in Acrp30/adiponectin structure and signaling specificity. Different oligomers activate different signal transduction pathways. J Biol Chem. (2003) 278:50810-7. doi: 10.1074/jbc.M309469200

7. Fruebis J, Tsao TS, Javorschi S, Ebbets-Reed D, Erickson MR, Yen FT, et al. Proteolytic cleavage product of $30-\mathrm{kDa}$ adipocyte complementrelated protein increases fatty acid oxidation in muscle and causes weight loss in mice. Proc Natl Acad Sci USA. (2001) 98:2005-10. doi: 10.1073/pnas.98.4.2005

8. Waki H, Yamauchi T, Kamon J, Kita S, Ito Y, Hada Y, et al. Generation of globular fragment of adiponectin by leukocyte elastase secreted by monocytic cell line THP-1. Endocrinology. (2005) 146:790-6. doi: 10.1210/en.2004-1096

9. Yamauchi T, Kamon J, Ito Y, Tsuchida A, Yokomizo T, Kita S, et al. Cloning of adiponectin receptors that mediate antidiabetic metabolic effects. Nature. (2003) 423:762-9. doi: 10.1038/nature01705 diseases. These pioneering studies provide an excellent guide in establishing a concept that will be applicable for future studies focused on adiponectin as a personalized therapeutic target.

In conclusion, merging what we know about adiponectin in disease pathophysiology, and mechanisms of action with new understandings of how utilizing AI can personalize medicine and improve outcomes, it is hoped that adiponectin-based therapeutics can be tailored as the best-in-class approach for managing metabolic health in the future (Figure 3).

\section{AUTHOR CONTRIBUTIONS}

All authors listed have made a substantial, direct and intellectual contribution to the work, and approved it for publication.

\section{ACKNOWLEDGMENTS}

Work in the corresponding authors laboratory on this topic was funded by Canadian Institutes of Health Research and also via a Career Investigator Award from Heart \& Stroke Foundation of Ontario. We would like to thank Kazoros Elizbaryan for his outstanding graphical skills in figure design.

10. Fang X, Palanivel R, Zhou X, Liu Y, Xu A, Wang Y, et al. Hyperglycemiaand hyperinsulinemia-induced alteration of adiponectin receptor expression and adiponectin effects in L6 myoblasts. J Mol Endocrinol. (2005) 35:465-76. doi: 10.1677/jme.1.01877

11. Yamauchi $T$, Nio $Y$, Maki $T$, Kobayashi M, Takazawa $T$, Iwabu $M$, et al. Targeted disruption of AdipoR1 and AdipoR2 causes abrogation of adiponectin binding and metabolic actions. Nat Med. (2007) 13:332-9. doi: $10.1038 / \mathrm{nm} 1557$

12. Bjursell M, Ahnmark A, Bohlooly YM, William-Olsson L, Rhedin M, Peng $\mathrm{XR}$, et al. Opposing effects of adiponectin receptors 1 and 2 on energy metabolism. Diabetes. (2007) 56:583-93. doi: 10.2337/db06-1432

13. Iwabu $M$, Yamauchi $T$, Okada-Iwabu $M$, Sato $K$, Nakagawa $T$, Funata $\mathrm{M}$, et al. Adiponectin and AdipoR1 regulate PGC-1alpha and mitochondria by $\mathrm{Ca}(2+)$ and AMPK/SIRT1. Nature. (2010) 464:1313-9. doi: 10.1038 /nature08991

14. Liu Y, Michael MD, Kash S, Bensch WR, Monia BP, Murray SF, et al. Deficiency of adiponectin receptor 2 reduces diet-induced insulin resistance but promotes type 2 diabetes. Endocrinology. (2007) 148:683-92. doi: 10.1210/en.2006-0708

15. Buechler C, Wanninger J, Neumeier M. Adiponectin receptor binding proteins-recent advances in elucidating adiponectin signalling pathways. FEBS Lett. (2010) 584:4280-6. doi: 10.1016/j.febslet.2010.09.035

16. Deepa SS, Dong LQ. APPL1: role in adiponectin signaling and beyond. Am J Physiol Endocrinol Metab. (2009) 296:E22-36. doi: 10.1152/ajpendo.90731.2008

17. Mao X, Kikani CK, Riojas RA, Langlais P, Wang L, Ramos FJ, et al. APPL1 binds to adiponectin receptors and mediates adiponectin signalling and function. Nat Cell Biol. (2006) 8:516-23. doi: 10.1038/ncb1404

18. Zhou L, Deepa SS, Etzler JC, Ryu J, Mao X, Fang Q, et al. Adiponectin activates AMP-activated protein kinase in muscle cells via APPL1/LKB1dependent and phospholipase $\mathrm{C} / \mathrm{Ca}^{2+} / \mathrm{Ca}^{2+} /$ calmodulin-dependent protein kinase kinase-dependent pathways. J Biol Chem. (2009) 284:22426-35. doi: 10.1074/jbc.M109.028357

19. Deepa SS, Zhou L, Ryu J, Wang C, Mao X, Li C, et al. APPL1 mediates adiponectin-induced LKB1 cytosolic localization through the PP2A-PKCzeta signaling pathway. Mol Endocrinol. (2011) 25:1773-85. doi: 10.1210/me.2011-0082 
20. Yamauchi T, Kamon J, Waki H, Terauchi Y, Kubota N, Hara K, et al. The fat-derived hormone adiponectin reverses insulin resistance associated with both lipoatrophy and obesity. Nat Med. (2001) 7:941-6. doi: 10.1038/90984

21. Tomas E, Tsao TS, Saha AK, Murrey HE, Zhang Cc C, Itani SI, et al. Enhanced muscle fat oxidation and glucose transport by ACRP30 globular domain: acetyl-CoA carboxylase inhibition and AMP-activated protein kinase activation. Proc Natl Acad Sci USA. (2002) 99:16309-13. doi: 10.1073/pnas.222657499

22. Yamauchi T, Kamon J, Minokoshi Y, Ito Y, Waki H, Uchida S, et al. Adiponectin stimulates glucose utilization and fatty-acid oxidation by activating AMP-activated protein kinase. Nat Med. (2002) 8:1288-95. doi: $10.1038 / \mathrm{nm} 788$

23. Yamauchi T, Kamon J, Waki H, Imai Y, Shimozawa N, Hioki K, et al. Globular adiponectin protected ob/ob mice from diabetes and ApoEdeficient mice from atherosclerosis. J Biol Chem. (2003) 278:2461-8. doi: 10.1074/jbc.M209033200

24. Civitarese AE, Ukropcova B, Carling S, Hulver M, DeFronzo RA, Mandarino $\mathrm{L}$, et al. Role of adiponectin in human skeletal muscle bioenergetics. Cell Metab. (2006) 4:75-87. doi: 10.1016/j.cmet.2006.05.002

25. Yoon MJ, Lee GY, Chung JJ, Ahn YH, Hong SH, Kim JB. Adiponectin increases fatty acid oxidation in skeletal muscle cells by sequential activation of AMP-activated protein kinase, p38 mitogen-activated protein kinase, and peroxisome proliferator-activated receptor alpha. Diabetes. (2006) 55:256270. doi: $10.2337 / \mathrm{db} 05-1322$

26. Fiaschi T, Cirelli D, Comito G, Gelmini S, Ramponi G, Serio M, et al. Globular adiponectin induces differentiation and fusion of skeletal muscle cells. Cell Res. (2009) 19:584-97. doi: 10.1038/cr.2009.39

27. Ruan H, Dong LQ. Adiponectin signaling and function in insulin target tissues. J Mol Cell Biol. (2016) 8:101-9. doi: 10.1093/jmcb/mjw014

28. Kadowaki T, Yamauchi T. Adiponectin and adiponectin receptors. Endocr Rev. (2005) 26:439-51. doi: 10.1210/er.2005-0005

29. Fang X, Sweeney G. Mechanisms regulating energy metabolism by adiponectin in obesity \& diabetes. Biochem Soc Trans. (2006) 34:798-801. doi: 10.1042/BST0340798

30. Yamauchi T, Kadowaki T. Physiological and pathophysiological roles of adiponectin and adiponectin receptors in the integrated regulation of metabolic and cardiovascular diseases. Int J Obes. (2008) 32:S13-8. doi: 10.1038/ijo.2008.233

31. Yanai H, Yoshida H. Beneficial effects of adiponectin on glucose and lipid metabolism and atherosclerotic progression: mechanisms and perspectives. Int J Mol Sci. (2019) 20:E1190. doi: 10.3390/ijms20051190

32. Park M, Sweeney G. Direct effects of adipokines on the heart: focus on adiponectin. Heart Fail Rev. (2013) 18:631-44. doi: 10.1007/s10741-012-9337-8

33. Okamoto Y, Kihara S, Ouchi N, Nishida M, Arita Y, Kumada M, et al. Adiponectin reduces atherosclerosis in apolipoprotein E-deficient mice. Circulation. (2002) 106:2767-70. doi: 10.1161/01.CIR.0000042707.50032.19

34. Gasbarrino K, Gorgui J, Nauche B, Cote R, Daskalopoulou SS. Circulating adiponectin and carotid intima-media thickness: a systematic review and meta-analysis. Metabolism. (2016) 65:968-86. doi: 10.1016/j.metabol.2016.03.008

35. Gorgui J, Gasbarrino K, Georgakis MK, Karalexi MA, Nauche B, Petridou ET, et al. Circulating adiponectin levels in relation to carotid atherosclerotic plaque presence, ischemic stroke risk, and mortality: a systematic review and meta-analyses. Metabolism. (2017) 69:51-66. doi: 10.1016/j.metabol.2017.01.002

36. Hui X, Lam KS, Vanhoutte PM, Xu A. Adiponectin and cardiovascular health: an update. Br J Pharmacol. (2012) 165:574-90. doi: 10.1111/j.1476-5381.2011.01395.x

37. Arita Y, Kihara S, Ouchi N, Maeda K, Kuriyama H, Okamoto Y, et al. Adipocyte-derived plasma protein adiponectin acts as a platelet-derived growth factor-BB-binding protein and regulates growth factor-induced common postreceptor signal in vascular smooth muscle cell. Circulation. (2002) 105:2893-8. doi: 10.1161/01.CIR.0000018622.84402.FF

38. Wang Y, Lam KS, Xu JY, Lu G, Xu LY, Cooper GJ, et al. Adiponectin inhibits cell proliferation by interacting with several growth factors in an oligomerization-dependent manner. J Biol Chem. (2005) 280:18341-7. doi: 10.1074/jbc.M501149200
39. Ouchi N, Kihara S, Arita Y, Nishida M, Matsuyama A, Okamoto Y, et al. Adipocyte-derived plasma protein, adiponectin, suppresses lipid accumulation and class A scavenger receptor expression in human monocyte-derived macrophages. Circulation. (2001) 103:1057-63. doi: 10.1161/01.CIR.103.8.1057

40. Furukawa K, Hori M, Ouchi N, Kihara S, Funahashi T, Matsuzawa Y, et al. Adiponectin down-regulates acyl-coenzyme A:cholesterol acyltransferase-1 in cultured human monocyte-derived macrophages. Biochem Biophys Res Commun. (2004) 317:831-6. doi: 10.1016/j.bbrc.2004.03.123

41. Lara-Castro C, Fu Y, Chung BH, Garvey WT. Adiponectin and the metabolic syndrome: mechanisms mediating risk for metabolic and cardiovascular disease. Curr Opin Lipidol. (2007) 18:263-70. doi: 10.1097/MOL.0b013e32814a645f

42. Tian L, Luo N, Klein RL, Chung BH, Garvey WT, Fu Y. Adiponectin reduces lipid accumulation in macrophage foam cells. Atherosclerosis. (2009) 202:152-61. doi: 10.1016/j.atherosclerosis.2008.04.011

43. Tian L, Luo N, Zhu X, Chung BH, Garvey WT, Fu Y. AdiponectinAdipoR1/2-APPL1 signaling axis suppresses human foam cell formation: differential ability of AdipoR1 and AdipoR2 to regulate inflammatory cytokine responses. Atherosclerosis. (2012) 221:66-75. doi: 10.1016/j.atherosclerosis.2011.12.014

44. Luo N, Chung BH, Wang X, Klein RL, Tang CK, Garvey WT, et al. Enhanced adiponectin actions by overexpression of adiponectin receptor 1 in macrophages. Atherosclerosis. (2013) 228:124-35. doi: 10.1016/j.atherosclerosis.2013.02.026

45. Stanley WC, Recchia FA, Lopaschuk GD. Myocardial substrate metabolism in the normal and failing heart. Physiol Rev. (2005) 85:1093-129. doi: 10.1152/physrev.00006.2004

46. Palanivel R, Fang X, Park M, Eguchi M, Pallan S, De Girolamo S, et al Globular and full-length forms of adiponectin mediate specific changes in glucose and fatty acid uptake and metabolism in cardiomyocytes. Cardiovasc Res. (2007) 75:148-57. doi: 10.1016/j.cardiores.2007.04.011

47. Fang X, Palanivel R, Cresser J, Schram K, Ganguly R, Thong FS, et al. An APPL1-AMPK signaling axis mediates beneficial metabolic effects of adiponectin in the heart. Am J Physiol Endocrinol Metab. (2010) 299:E721-9. doi: 10.1152/ajpendo.00086.2010

48. Palanivel R, Ganguly R, Turdi S, Xu A, Sweeney G. Adiponectin stimulates Rho-mediated actin cytoskeleton remodeling and glucose uptake via APPL1 in primary cardiomyocytes. Metabolism. (2014) 63:1363-73. doi: 10.1016/j.metabol.2014.07.005

49. Onay-Besikci A, Altarejos JY, Lopaschuk GD. gAd-globular head domain of adiponectin increases fatty acid oxidation in newborn rabbit hearts. J Biol Chem. (2004) 279:44320-6. doi: 10.1074/jbc.M400347200

50. Fu Y, Luo N, Klein RL, Garvey WT. Adiponectin promotes adipocyte differentiation, insulin sensitivity, and lipid accumulation. J Lipid Res. (2005) 46:1369-79. doi: 10.1194/jlr.M400373-JLR200

51. Ding G, Qin Q, He N, Francis-David SC, Hou J, Liu J, et al. Adiponectin and its receptors are expressed in adult ventricular cardiomyocytes and upregulated by activation of peroxisome proliferatoractivated receptor gamma. J Mol Cell Cardiol. (2007) 43:73-84. doi: 10.1016/j.yjmcc.2007.04.014

52. Botta A, Liu Y, Wannaiampikul S, Tungtrongchitr R, Dadson K, Park TS, et al. An adiponectin-S1P axis protects against lipid induced insulin resistance and cardiomyocyte cell death via reduction of oxidative stress. Nutr Metab (Lond). (2019) 16:14. doi: 10.1186/s12986-0190342-y

53. Skurk C, Wittchen F, Suckau L, Witt H, Noutsias M, Fechner H, et al. Description of a local cardiac adiponectin system and its deregulation in dilated cardiomyopathy. Eur Heart J. (2008) 29:1168-80. doi: 10.1093/eurheartj/ehn136

54. Tao L, Gao E, Jiao X, Yuan Y, Li S, Christopher TA, et al. Adiponectin cardioprotection after myocardial ischemia/reperfusion involves the reduction of oxidative/nitrative stress. Circulation. (2007) 115:1408-16. doi: 10.1161/CIRCULATIONAHA.106.666941

55. Park M, Youn B, Zheng XL, Wu D, Xu A, Sweeney G. Globular adiponectin, acting via AdipoR1/APPL1, protects $\mathrm{H} 9 \mathrm{c} 2$ cells from hypoxia/reoxygenation-induced apoptosis. PLoS ONE. (2011) 6:e19143. doi: 10.1371/journal.pone.0019143 
56. Holland WL, Miller RA, Wang ZV, Sun K, Barth BM, Bui HH, et al. Receptormediated activation of ceramidase activity initiates the pleiotropic actions of adiponectin. Nat Med. (2011) 17:55-63. doi: 10.1038/nm.2277

57. Essick EE, Wilson RM, Pimentel DR, Shimano M, Baid S, Ouchi N, et al. Adiponectin modulates oxidative stress-induced autophagy in cardiomyocytes. PLoS ONE. (2013) 8:e68697. doi: 10.1371/journal.pone.0068697

58. Guo R, Zhang Y, Turdi S, Ren J. Adiponectin knockout accentuates high fat diet-induced obesity and cardiac dysfunction: role of autophagy. Biochim Biophys Acta. (2013) 1832:1136-48. doi: 10.1016/j.bbadis.2013. 03.013

59. Jahng JW, Turdi S, Kovacevic V, Dadson K, Li RK, Sweeney G. Pressure overload-induced cardiac dysfunction in aged male adiponectin knockout mice is associated with autophagy deficiency. Endocrinology. (2015) 156:2667-77. doi: 10.1210/en.2015-1162

60. Ren J, Xu X, Wang Q, Ren SY, Dong M, Zhang Y. Permissive role of AMPK and autophagy in adiponectin deficiency-accentuated myocardial injury and inflammation in endotoxemia. J Mol Cell Cardiol. (2016) 93:18-31. doi: 10.1016/j.yjmcc.2016.02.002

61. Shibata R, Ouchi N, Ito M, Kihara S, Shiojima I, Pimentel DR, et al. Adiponectin-mediated modulation of hypertrophic signals in the heart. Nat Med. (2004) 10:1384-9. doi: 10.1038/nm1137

62. Shimano M, Ouchi N, Shibata R, Ohashi K, Pimentel DR, Murohara T, et al. Adiponectin deficiency exacerbates cardiac dysfunction following pressure overload through disruption of an AMPK-dependent angiogenic response. $J$ Mol Cell Cardiol. (2010) 49:210-20. doi: 10.1016/j.yjmcc.2010.02.021

63. Dadson K, Turdi S, Hashemi S, Zhao J, Polidovitch N, Beca S, et al. Adiponectin is required for cardiac MEF2 activation during pressure overload induced hypertrophy. J Mol Cell Cardiol. (2015) 86:102-9. doi: 10.1016/j.yjmcc.2015.06.020

64. Wang C, Li L, Zhang ZG, Fan D, Zhu Y, Wu LL. Globular adiponectin inhibits angiotensin II-induced nuclear factor kappaB activation through AMP-activated protein kinase in cardiac hypertrophy. J Cell Physiol. (2010) 222:149-55. doi: 10.1002/jcp.21931

65. Cao T, Gao Z, Gu L, Chen M, Yang B, Cao K, et al. AdipoR1/APPL1 potentiates the protective effects of globular adiponectin on angiotensin IIinduced cardiac hypertrophy and fibrosis in neonatal rat atrial myocytes and fibroblasts. PLoS ONE. (2014) 9:e103793. doi: 10.1371/journal.pone.0103793

66. Li Y, Cai X, Guan Y, Wang L, Wang S, Li Y, et al. Adiponectin upregulates MiR-133a in cardiac hypertrophy through AMPK activation and reduced ERK1/2 phosphorylation. PLoS ONE. (2016) 11:e0148482. doi: 10.1371/journal.pone.0148482

67. Arita Y, Kihara S, Ouchi N, Takahashi M, Maeda K, Miyagawa J, et al. Paradoxical decrease of an adipose-specific protein, adiponectin, in obesity. Biochem Biophys Res Commun. (1999) 257:79-83. doi: 10.1006/bbrc.1999.0255

68. Luo M, Oza-Frank R, Narayan KM, Gokulakrishnan K, Mohan V. Serum total adiponectin is associated with impaired glucose tolerance in Asian Indian females but not in males. J Diabetes Sci Technol. (2010) 4:645-51. doi: $10.1177 / 193229681000400319$

69. Gabrielsen JS, Gao Y, Simcox JA, Huang J, Thorup D, Jones D, et al. Adipocyte iron regulates adiponectin and insulin sensitivity. J Clin Invest. (2012) 122:3529-40. doi: 10.1172/JCI44421

70. de Almeida-Pititto B, Ribeiro-Filho FF, Santos IS, Lotufo PA, Bensenor IM, Ferreira SR. Association between carotid intima-media thickness and adiponectin in participants without diabetes or cardiovascular disease of the Brazilian Longitudinal Study of Adult Health (ELSA-Brasil). Eur J Prev Cardiol. (2017) 24:116-22. doi: 10.1177/2047487316665490

71. Lara-Castro C, Luo N, Wallace P, Klein RL, Garvey WT. Adiponectin multimeric complexes and the metabolic syndrome trait cluster. Diabetes. (2006) 55:249-59. doi: 10.2337/diabetes.55.01.06.db05-1105

72. Gokulakrishnan K, Indulekha K, Ganesan S, Anuradha S, Mohan V. Adiponectin and carotid intimal medial thickness in subjects with and without glucose intolerance (CURES-82). Diabetes Technol Ther. (2010) 12:109-15. doi: 10.1089/dia.2009.0100

73. Djousse L, Wilk JB, Hanson NQ, Glynn RJ, Tsai MY, Gaziano JM. Association between adiponectin and heart failure risk in the physicians' health study. Obesity (Silver Spring). (2013) 21:831-4. doi: 10.1002/oby.20260
74. Iglseder B, Mackevics V, Stadlmayer A, Tasch G, Ladurner G, Paulweber B. Plasma adiponectin levels and sonographic phenotypes of subclinical carotid artery atherosclerosis: data from the SAPHIR Study. Stroke. (2005) 36:2577-82. doi: 10.1161/01.STR.0000190834.00284.fd

75. Laughlin GA, Barrett-Connor E, May S, Langenberg C. Association of adiponectin with coronary heart disease and mortality: the Rancho Bernardo study. Am J Epidemiol. (2007) 165:164-74. doi: 10.1093/aje/kwk001

76. Lindberg S, Mogelvang R, Pedersen SH, Bjerre M, Frystyk J, Flyvbjerg A, et al. Relation of serum adiponectin levels to number of traditional atherosclerotic risk factors and all-cause mortality and major adverse cardiovascular events (from the Copenhagen City Heart Study). Am J Cardiol. (2013) 111:1139-45. doi: 10.1016/j.amjcard.2012.12.043

77. Lindberg S, Jensen JS, Bjerre M, Pedersen SH, Frystyk J, Flyvbjerg A, et al. Adiponectin, type 2 diabetes and cardiovascular risk. Eur J Prev Cardiol. (2015) 22:276-83. doi: 10.1177/2047487313514894

78. Kojima S, Funahashi T, Otsuka F, Maruyoshi H, Yamashita T, Kajiwara I, et al. Future adverse cardiac events can be predicted by persistently low plasma adiponectin concentrations in men and marked reductions of adiponectin in women after acute myocardial infarction. Atherosclerosis. (2007) 194:204-13. doi: 10.1016/j.atherosclerosis.2006.07.028

79. Huang SS, Huang PH, Chen YH, Chiang KH, Chen JW, Lin SJ. Association of adiponectin with future cardiovascular events in patients after acute myocardial infarction. J Atheroscler Thromb. (2010) 17:295-303. doi: $10.5551 /$ jat. 3533

80. Lindberg S, Jensen JS, Bjerre M, Pedersen SH, Frystyk J, Flyvbjerg A, et al. Cardio-adipose tissue cross-talk: relationship between adiponectin, plasma pro brain natriuretic peptide and incident heart failure. Eur J Heart Fail. (2014) 16:633-8. doi: 10.1002/ejhf.82

81. Bergmark BA, Cannon CP, White WB, Jarolim P, Liu Y, Bonaca MP, et al. Baseline adiponectin concentration and clinical outcomes among patients with diabetes and recent acute coronary syndrome in the EXAMINE trial. Diabetes Obes Metab. (2017) 19:962-9. doi: 10.1111/dom.12905

82. Kistorp C, Faber J, Galatius S, Gustafsson F, Frystyk J, Flyvbjerg A, et al. Plasma adiponectin, body mass index, and mortality in patients with chronic heart failure. Circulation. (2005) 112:1756-62. doi: 10.1161/CIRCULATIONAHA.104.530972

83. Wannamethee SG, Whincup PH, Lennon L, Sattar N. Circulating adiponectin levels and mortality in elderly men with and without cardiovascular disease and heart failure. Arch Intern Med. (2007) 167:1510-7. doi: 10.1001/archinte.167.14.1510

84. Kizer JR, Benkeser D, Arnold AM, Mukamal KJ, Ix JH, Zieman SJ, et al. Associations of total and high-molecular-weight adiponectin with all-cause and cardiovascular mortality in older persons: the Cardiovascular Health Study. Circulation. (2012) 126:2951-61. doi: 10.1161/CIRCULATIONAHA.112.135202

85. Sente T, Van Berendoncks AM, Hoymans VY, Vrints CJ. Adiponectin resistance in skeletal muscle: pathophysiological implications in chronic heart failure. J Cachexia Sarcopenia Muscle. (2016) 7:261-74. doi: $10.1002 / \mathrm{jcsm} .12086$

86. Wang Y, Ma XL, Lau WB. Cardiovascular adiponectin resistance: the critical role of adiponectin receptor modification. Trends Endocrinol Metab. (2017) 28:519-30. doi: 10.1016/j.tem.2017.03.004

87. Behre CJ. Adiponectin: saving the starved and the overfed. Med Hypotheses. (2007) 69:1290-2. doi: 10.1016/j.mehy.2007.02.044

88. McEntegart MB, Awede B, Petrie MC, Sattar N, Dunn FG, MacFarlane $\mathrm{NG}$, et al. Increase in serum adiponectin concentration in patients with heart failure and cachexia: relationship with leptin, other cytokines, and B-type natriuretic peptide. Eur Heart J. (2007) 28:829-35. doi: 10.1093/eurheartj/ehm033

89. Wu W, Shi F, Liu D, Ceddia RP, Gaffin R, Wei W, et al. Enhancing natriuretic peptide signaling in adipose tissue, but not in muscle, protects against diet-induced obesity and insulin resistance. Sci Signal. (2017) 10:eaam6870. doi: 10.1126/scisignal.aam6870

90. Sengenes C, Berlan M, De Glisezinski I, Lafontan M, Galitzky J. Natriuretic peptides: a new lipolytic pathway in human adipocytes. FASEB J. (2000) 14:1345-51. doi: 10.1096/fasebj.14.10.1345

91. Bordicchia M, Liu D, Amri EZ, Ailhaud G, Dessi-Fulgheri P, Zhang C, et al. Cardiac natriuretic peptides act via p38 MAPK to induce the brown fat 
thermogenic program in mouse and human adipocytes. J Clin Invest. (2012) 122:1022-36. doi: 10.1172/JCI59701

92. Tsukamoto O, Fujita M, Kato M, Yamazaki S, Asano Y, Ogai A, et al. Natriuretic peptides enhance the production of adiponectin in human adipocytes and in patients with chronic heart failure. J Am Coll Cardiol. (2009) 53:2070-7. doi: 10.1016/j.jacc.2009.02.038

93. Birkenfeld AL, Boschmann M, Engeli S, Moro C, Arafat AM, Luft FC, et al. Atrial natriuretic peptide and adiponectin interactions in man. PLoS ONE. (2012) 7:e43238. doi: 10.1371/journal.pone.0043238

94. Ichida K, Moriyama T, Morita H, Kondo T, Yoshida S, Ohara N, et al. Plasma adiponectin concentrations and placental adiponectin expression in pre-eclamptic women. Gynecol Endocrinol. (2007) 23:238-43. doi: 10.1080/09513590701297740

95. Antonopoulos AS, Margaritis M, Coutinho P, Digby J, Patel R, Psarros C, et al. Reciprocal effects of systemic inflammation and brain natriuretic peptide on adiponectin biosynthesis in adipose tissue of patients with ischemic heart disease. Arterioscler Thromb Vasc Biol. (2014) 34:2151-9. doi: 10.1161/ATVBAHA.114.303828

96. Lawlor DA, Davey Smith G, Ebrahim S, Thompson C, Sattar N. Plasma adiponectin levels are associated with insulin resistance, but do not predict future risk of coronary heart disease in women. J Clin Endocrinol Metab. (2005) 90:5677-83. doi: 10.1210/jc.2005-0825

97. Hao G, Li W, Guo R, Yang JG, Wang Y, Tian Y, et al. Serum total adiponectin level and the risk of cardiovascular disease in general population: a meta-analysis of 17 prospective studies. Atherosclerosis. (2013) 228:29-35. doi: 10.1016/j.atherosclerosis.2013.02.018

98. Woodward L, Akoumianakis I, Antoniades C. Unravelling the adiponectin paradox: novel roles of adiponectin in the regulation of cardiovascular disease. Br J Pharmacol. (2017) 174:4007-20. doi: 10.1111/bph.13619

99. Menzaghi C, Trischitta V. The adiponectin paradox for all-cause and cardiovascular mortality. Diabetes. (2018) 67:12-22. doi: 10.2337/dbi17-0016

100. Hoffstedt J, Arvidsson E, Sjolin E, Wahlen K, Arner P. Adipose tissue adiponectin production and adiponectin serum concentration in human obesity and insulin resistance. J Clin Endocrinol Metab. (2004) 89:1391-6. doi: 10.1210/jc.2003-031458

101. Halberg N, Schraw TD, Wang ZV, Kim JY, Yi J, Hamilton MP, et al. Systemic fate of the adipocyte-derived factor adiponectin. Diabetes. (2009) 58:196170. doi: $10.2337 / \mathrm{db} 08-1750$

102. Gadde KM, Allison DB, Ryan DH, Peterson CA, Troupin B, Schwiers ML, et al. Effects of low-dose, controlled-release, phentermine plus topiramate combination on weight and associated comorbidities in overweight and obese adults (CONQUER): a randomised, placebo-controlled, phase 3 trial. Lancet. (2011) 377:1341-52. doi: 10.1016/S0140-6736(11)60205-5

103. Garvey WT, Ryan DH, Henry R, Bohannon NJ, Toplak H, Schwiers M, et al. Prevention of type 2 diabetes in subjects with prediabetes and metabolic syndrome treated with phentermine and topiramate extended release. Diabetes Care. (2014) 37:912-21. doi: 10.2337/dc13-1518

104. Gomez-Martin JM, Balsa JA, Aracil E, Insenser M, Priego P, EscobarMorreale HF, et al. Circulating adiponectin increases in obese women after sleeve gastrectomy or gastric bypass driving beneficial metabolic changes but with no relationship with carotid intima-media thickness. Clin Nutr. (2018) 37:2102-6. doi: 10.1016/j.clnu.2017.10.003

105. Lips MA, van Klinken JB, Pijl H, Janssen I, Willems van Dijk K, Koning $\mathrm{F}$, et al. Weight loss induced by very low calorie diet is associated with a more beneficial systemic inflammatory profile than by Roux-en-Y gastric bypass. Metabolism. (2016) 65:1614-20. doi: 10.1016/j.metabol.2016. 07.013

106. Kriketos AD, Gan SK, Poynten AM, Furler SM, Chisholm DJ, Campbell LV. Exercise increases adiponectin levels and insulin sensitivity in humans. Diabetes Care. (2004) 27:629-30. doi: 10.2337/diacare.27.2.629

107. Kondo T, Kobayashi I, Murakami M. Effect of exercise on circulating adipokine levels in obese young women. Endocr J. (2006) 53:189-95. doi: 10.1507/endocrj.53.189

108. Ring-Dimitriou S, Paulweber B, von Duvillard SP, Stadlmann M, LeMura LM, Lang J, et al. The effect of physical activity and physical fitness on plasma adiponectin in adults with predisposition to metabolic syndrome. Eur J Appl Physiol. (2006) 98:472-81. doi: 10.1007/s00421-006-0291-9
109. Vu V, Riddell MC, Sweeney G. Circulating adiponectin and adiponectin receptor expression in skeletal muscle: effects of exercise. Diabetes Metab Res Rev. (2007) 23:600-11. doi: 10.1002/dmrr.778

110. Riera-Guardia N, Rothenbacher D. The effect of thiazolidinediones on adiponectin serum level: a meta-analysis. Diabetes Obes Metab. (2008) 10:367-75. doi: 10.1111/j.1463-1326.2007.00755.x

111. Amin RH, Mathews ST, Camp HS, Ding L, Leff T. Selective activation of PPARgamma in skeletal muscle induces endogenous production of adiponectin and protects mice from diet-induced insulin resistance. Am J Physiol Endocrinol Metab. (2010) 298:E28-37. doi: 10.1152/ajpendo.00446.2009

112. Qian X, Wang H, Yang G, Gao Z, Luo Y, Dong A, et al. Pioglitazone improved insulin sensitivity and first phase insulin secretion among obese and lean people with diabetes: a multicenter clamp study. Diabetes Ther. (2018) 9:815-26. doi: 10.1007/s13300-018-0401-9

113. Tripathy D, Clement SC, Schwenke DC, Banerji M, Bray GA, Buchanan $\mathrm{TA}$, et al. Baseline adiponectin levels do not influence the response to pioglitazone in ACT NOW. Diabetes Care. (2014) 37:1706-11. doi: $10.2337 / \mathrm{dc1} 13-1745$

114. Esteghamati A, Azizi R, Ebadi M, Noshad S, Mousavizadeh M, Afarideh $\mathrm{M}$, et al. The comparative effect of pioglitazone and metformin on serum osteoprotegerin, adiponectin and intercellular adhesion molecule concentrations in patients with newly diagnosed type 2 diabetes: a randomized clinical trial. Exp Clin Endocrinol Diabetes. (2015) 123:289-95. doi: 10.1055/s-0034-1396864

115. Espinoza SE, Wang CP, Tripathy D, Clement SC, Schwenke DC, Banerji MA, et al. Pioglitazone is equally effective for diabetes prevention in older versus younger adults with impaired glucose tolerance. Age (Dordr). (2016) 38:485-93. doi: 10.1007/s11357-016-9946-6

116. Punthakee Z, Almeras N, Despres JP, Dagenais GR, Anand SS, Hunt DL, et al. Impact of rosiglitazone on body composition, hepatic fat, fatty acids, adipokines and glucose in persons with impaired fasting glucose or impaired glucose tolerance: a sub-study of the DREAM trial. Diabet Med. (2014) 31:1086-92. doi: 10.1111/dme.12512

117. Bodles AM, Banga A, Rasouli N, Ono F, Kern PA, Owens RJ. Pioglitazone increases secretion of high-molecular-weight adiponectin from adipocytes. Am J Physiol Endocrinol Metab. (2006) 291:E1100-5. doi: 10.1152/ajpendo.00187.2006

118. Phillips SA, Kung J, Ciaraldi TP, Choe C, Christiansen L, Mudaliar S, et al. Selective regulation of cellular and secreted multimeric adiponectin by antidiabetic therapies in humans. Am J Physiol Endocrinol Metab. (2009) 297:E767-773. doi: 10.1152/ajpendo.00378.2009

119. Chaggar PS, Shaw SM, Williams SG. Review article: Thiazolidinediones and heart failure. Diab Vasc Dis Res. (2009) 6:146-52. doi: $10.1177 / 1479164109338772$

120. Rizos CV, Elisaf MS, Mikhailidis DP, Liberopoulos EN. How safe is the use of thiazolidinediones in clinical practice? Expert Opin Drug Saf. (2009) 8:15-32. doi: 10.1517/14740330802597821

121. Landrier JF, Gouranton E, El Yazidi C, Malezet C, Balaguer P, Borel $\mathrm{P}$, et al. Adiponectin expression is induced by vitamin $\mathrm{E}$ via a peroxisome proliferator-activated receptor gamma-dependent mechanism. Endocrinology. (2009) 150:5318-25. doi: 10.1210/en.2009-0506

122. Matsunaga T, Shoji A, Gu N, Joo E, Li S, Adachi T, et al. gamma-Tocotrienol attenuates TNF-alpha-induced changes in secretion and gene expression of MCP-1, IL-6 and adiponectin in 3T3-L1 adipocytes. Mol Med Rep. (2012) 5:905-9. doi: 10.3892/mmr.2012.770

123. Wu JH, Cahill LE, Mozaffarian D. Effect of fish oil on circulating adiponectin: a systematic review and meta-analysis of randomized controlled trials. J Clin Endocrinol Metab. (2013) 98:2451-9. doi: 10.1210/jc.2012-3899

124. Bahreini M, Ramezani AH, Shishehbor F, Mansoori A. The effect of omega3 on circulating adiponectin in adults with type 2 diabetes mellitus: a systematic review and meta-analysis of randomized controlled trials. Can J Diabetes. (2018) 42:553-9. doi: 10.1016/j.jcjd.2017.12.002

125. Becic T, Studenik C. Effects of omega-3 supplementation on adipocytokines in prediabetes and type 2 diabetes mellitus: systematic review and metaanalysis of randomized controlled trials. Diabetes Metab J. (2018) 42:101-16. doi: 10.4093/dmj.2018.42.2.101 
126. Hatano T, Sameshima Y, Kawabata M, Yamada S, Shinozuka K, Nakabayashi T, et al. St. John's wort promotes adipocyte differentiation and modulates NF-kappaB activation in 3T3-L1 cells. Biol Pharm Bull. (2014) 37:1132-8. doi: 10.1248/bpb.b13-00989

127. Boudreau A, Fuller S, Ribnicky DM, Richard AJ, Stephens JM. Groundsel bush (Baccharis halimifolia) extract promotes adipocyte differentiation in vitro and increases adiponectin expression in mature adipocytes. Biology (Basel). (2018) 7:E22. doi: 10.3390/biology7020022

128. Terra X, Montagut G, Bustos M, Llopiz N, Ardevol A, Blade C, et al. Grapeseed procyanidins prevent low-grade inflammation by modulating cytokine expression in rats fed a high-fat diet. J Nutr Biochem. (2009) 20:210-8. doi: 10.1016/j.jnutbio.2008.02.005

129. Meeprom A, Sompong W, Suwannaphet W, Yibchok-anun S, Adisakwattana S. Grape seed extract supplementation prevents high-fructose diet-induced insulin resistance in rats by improving insulin and adiponectin signalling pathways. Br J Nutr. (2011) 106:1173-81. doi: 10.1017/S0007114511001589

130. Pascual-Serrano A, Arola-Arnal A, Suarez-Garcia S, Bravo FI, Suarez M, Arola L, et al. Grape seed proanthocyanidin supplementation reduces adipocyte size and increases adipocyte number in obese rats. Int J Obes (Lond). (2017) 41:1246-55. doi: 10.1038/ijo.2017.90

131. Hsu CH, Tsai TH, Kao YH, Hwang KC, Tseng TY, Chou P. Effect of green tea extract on obese women: a randomized, double-blind, placebo-controlled clinical trial. Clin Nutr. (2008) 27:363-70. doi: 10.1016/j.clnu.2008.03.007

132. Izadi V, Larijani B, Azadbakht L. Is coffee and green tea consumption related to serum levels of adiponectin and leptin? Int J Prev Med. (2018) 9:106. doi: 10.4103/ijpvm.IJPVM_37_14

133. Aronis KN, Vamvini MT, Chamberland JP, Sweeney LL, Brennan AM, Magkos F, et al. Short-term walnut consumption increases circulating total adiponectin and apolipoprotein A concentrations, but does not affect markers of inflammation or vascular injury in obese humans with the metabolic syndrome: data from a double-blinded, randomized, placebo-controlled study. Metabolism. (2012) 61:577-82. doi: 10.1016/j.metabol.2011.09.008

134. Hwang HJ, Liu Y, Kim HS, Lee H, Lim Y, Park H. Daily walnut intake improves metabolic syndrome status and increases circulating adiponectin levels: randomized controlled crossover trial. Nutr Res Pract. (2019) 13:10514. doi: 10.4162/nrp.2019.13.2.105

135. Gomes PM, Hollanda-Miranda WR, Beraldo RA, Castro AV, Geloneze B, Foss MC, et al. Supplementation of alpha-linolenic acid improves serum adiponectin levels and insulin sensitivity in patients with type 2 diabetes. Nutrition. (2015) 31:853-7. doi: 10.1016/j.nut.2014.12.028

136. Mohammadi-Sartang M, Mazloom Z, Sohrabi Z, Sherafatmanesh S, Barati-Boldaji R. Resveratrol supplementation and plasma adipokines concentrations? A systematic review and meta-analysis of randomized controlled trials. Pharmacol Res. (2017) 117:394-405. doi: 10.1016/j.phrs.2017.01.012

137. Wicinski M, Malinowski B, Weclewicz MM, Grzesk E, Grzesk G. Antiatherogenic properties of resveratrol: 4-week resveratrol administration associated with serum concentrations of SIRT1, adiponectin, S100A8/A9 and VSMCs contractility in a rat model. Exp Ther Med. (2017) 13:2071-8. doi: 10.3892/etm.2017.4180

138. Jimoh A, Tanko Y, Ayo JO, Ahmed A, Mohammed A. Resveratrol increases serum adiponectin level and decreases leptin and insulin level in an experimental model of hypercholesterolemia. Pathophysiology. (2018) 25:411-7. doi: 10.1016/j.pathophys.2018.08.005

139. Xu A, Wang H, Hoo RL, Sweeney G, Vanhoutte PM, Wang Y, et al. Selective elevation of adiponectin production by the natural compounds derived from a medicinal herb alleviates insulin resistance and glucose intolerance in obese mice. Endocrinology. (2009) 150:625-33. doi: 10.1210/en.2008-0999

140. Tian F, Luo R, Zhao Z, Wu Y, Ban D. Blockade of the RAS increases plasma adiponectin in subjects with metabolic syndrome and enhances differentiation and adiponectin expression of human preadipocytes. Exp Clin Endocrinol Diabetes. (2010) 118:258-65. doi: 10.1055/s-00291237706

141. Furuhashi M, Ura N, Higashiura K, Murakami H, Tanaka M, Moniwa $\mathrm{N}$, et al. Blockade of the renin-angiotensin system increases adiponectin concentrations in patients with essential hypertension. Hypertension. (2003) 42:76-81. doi: 10.1161/01.HYP.0000078490.59735.6E
142. Clasen R, Schupp M, Foryst-Ludwig A, Sprang C, Clemenz M, Krikov $M$, et al. PPARgamma-activating angiotensin type-1 receptor blockers induce adiponectin. Hypertension. (2005) 46:137-43. doi: 10.1161/01.HYP.0000168046.19884.6a

143. Kim Chung le T, Hosaka T, Yoshida M, Harada N, Sakaue H, Sakai T, et al. Exendin-4, a GLP-1 receptor agonist, directly induces adiponectin expression through protein kinase A pathway and prevents inflammatory adipokine expression. Biochem Biophys Res Commun. (2009) 390:613-8. doi: 10.1016/j.bbrc.2009.10.015

144. Sahebkar A, Ponzo V, Bo S. Effect of dipeptidyl peptidase-4 inhibitors on plasma adiponectin: a systematic review and meta-analysis of randomized controlled trials. Curr Med Chem. (2016) 23:1356-69. doi: 10.2174/0929867323666160405111354

145. Nishida K, Okada Y, Nawata M, Saito K, Tanaka Y. Induction of hyperadiponectinemia following long-term treatment of patients with rheumatoid arthritis with infliximab (IFX), an anti-TNF-alpha antibody. Endocr J. (2008) 55:213-6. doi: 10.1507/endocrj.K07E-043

146. Chrusciel P, Sahebkar A, Rembek-Wieliczko M, Serban MC, Ursoniu S, Mikhailidis DP, et al. Impact of statin therapy on plasma adiponectin concentrations: a systematic review and meta-analysis of 43 randomized controlled trial arms. Atherosclerosis. (2016) 253:194-208. doi: 10.1016/j.atherosclerosis.2016.07.897

147. Tahara A, Takasu T, Yokono M, Imamura M, Kurosaki E. Characterization and comparison of sodium-glucose cotransporter 2 inhibitors: part 2. Antidiabetic effects in type 2 diabetic mice. J Pharmacol Sci. (2016) 131:198208. doi: 10.1016/j.jphs.2016.06.004

148. Han JH, Oh TJ, Lee G, Maeng HJ, Lee DH, Kim KM, et al. The beneficial effects of empagliflozin, an SGLT2 inhibitor, on atherosclerosis in ApoE (-/-) mice fed a western diet. Diabetologia. (2017) 60:364-76. doi: 10.1007/s00125-016-4158-2

149. Tsuchida A, Yamauchi T, Takekawa S, Hada Y, Ito Y, Maki T, et al. Peroxisome proliferator-activated receptor (PPAR)alpha activation increases adiponectin receptors and reduces obesity-related inflammation in adipose tissue: comparison of activation of PPARalpha, PPARgamma, and their combination. Diabetes. (2005) 54:3358-70. doi: 10.2337/diabetes.54. 12.3358

150. Chinetti G, Zawadski C, Fruchart JC, Staels B. Expression of adiponectin receptors in human macrophages and regulation by agonists of the nuclear receptors PPARalpha, PPARgamma, and LXR. Biochem Biophys Res Commun. (2004) 314:151-8. doi: 10.1016/j.bbrc.2003.12.058

151. Coletta DK, Sriwijitkamol A, Wajcberg E, Tantiwong P, Li M, Prentki $\mathrm{M}$, et al. Pioglitazone stimulates AMP-activated protein kinase signalling and increases the expression of genes involved in adiponectin signalling, mitochondrial function and fat oxidation in human skeletal muscle in vivo: a randomised trial. Diabetologia. (2009) 52:723-32. doi: 10.1007/s00125-008-1256-9

152. Guo Z, Zhang R, Li J, Xu G. Effect of telmisartan on the expression of adiponectin receptors and nicotinamide adenine dinucleotide phosphate oxidase in the heart and aorta in type 2 diabetic rats. Cardiovasc Diabetol. (2012) 11:94. doi: 10.1186/1475-2840-11-94

153. Metais C, Forcheron F, Abdallah P, Basset A, Del Carmine P, Bricca $\mathrm{G}$, et al. Adiponectin receptors: expression in Zucker diabetic rats and effects of fenofibrate and metformin. Metabolism. (2008) 57:946-53. doi: 10.1016/j.metabol.2008.02.010

154. Huang $\mathrm{H}$, Iida $\mathrm{KT}$, Sone $\mathrm{H}$, Yokoo $\mathrm{T}$, Yamada $\mathrm{N}$, Ajisaka R. The effect of exercise training on adiponectin receptor expression in KKAy obese/diabetic mice. J Endocrinol. (2006) 189:643-53. doi: 10.1677/joe. 1.06630

155. Zeng Q, Isobe K, Fu L, Ohkoshi N, Ohmori H, Takekoshi K, et al. Effects of exercise on adiponectin and adiponectin receptor levels in rats. Life Sci. (2007) 80:454-9. doi: 10.1016/j.lfs.2006.09.031

156. Bluher M, Bullen JW Jr, Lee JH, Kralisch S, Fasshauer M, Kloting N, et al. Circulating adiponectin and expression of adiponectin receptors in human skeletal muscle: associations with metabolic parameters and insulin resistance and regulation by physical training. J Clin Endocrinol Metab. (2006) 91:2310-6. doi: 10.1210/jc.2005-2556

157. O'Leary VB, Jorett AE, Marchetti CM, Gonzalez F, Phillips SA, Ciaraldi $\mathrm{TP}$, et al. Enhanced adiponectin multimer ratio and skeletal muscle 
adiponectin receptor expression following exercise training and diet in older insulin-resistant adults. Am J Physiol Endocrinol Metab. (2007) 293:E421-7. doi: 10.1152/ajpendo.00123.2007

158. Xu A, Sweeney G. Emerging role of autophagy in mediating widespread actions of ADIPOQ/adiponectin. Autophagy. (2015) 11:723-4. doi: $10.1080 / 15548627.2015 .1034418$

159. Wu X, Motoshima H, Mahadev K, Stalker TJ, Scalia R, Goldstein BJ. Involvement of AMP-activated protein kinase in glucose uptake stimulated by the globular domain of adiponectin in primary rat adipocytes. Diabetes. (2003) 52:1355-63. doi: 10.2337/diabetes.52.6.1355

160. Otvos L Jr, Knappe D, Hoffmann R, Kovalszky I, Olah J, Hewitson TD, et al. Development of second generation peptides modulating cellular adiponectin receptor responses. Front Chem. (2014) 2:93. doi: 10.3389/fchem.2014.00093

161. Otvos L Jr, Haspinger E, La Russa F, Maspero F, Graziano P, Kovalszky I, et al. Design and development of a peptide-based adiponectin receptor agonist for cancer treatment. BMC Biotechnol. (2011) 11:90. doi: 10.1186/1472-6750-11-90

162. Okada-Iwabu M, Yamauchi T, Iwabu M, Honma T, Hamagami K, Matsuda $\mathrm{K}$, et al. A small-molecule AdipoR agonist for type 2 diabetes and short life in obesity. Nature. (2013) 503:493-9. doi: 10.1038/nature12656

163. Okada-Iwabu M, Iwabu M, Ueki K, Yamauchi T, Kadowaki T. Perspective of small-molecule AdipoR agonist for type 2 diabetes and short life in obesity. Diabetes Metab J. (2015) 39:363-72. doi: 10.4093/dmj.2015.39.5.363

164. Wang Y, Wan Y, Ye G, Wang P, Xue X, Wu G, et al. Hepatoprotective effects of AdipoRon against d-galactosamine-induced liver injury in mice. Eur J Pharm Sci. (2016) 93:123-31. doi: 10.1016/j.ejps.2016.08.017

165. Yamashita T, Lakota K, Taniguchi T, Yoshizaki A, Sato S, Hong W, et al. An orally-active adiponectin receptor agonist mitigates cutaneous fibrosis, inflammation and microvascular pathology in a murine model of systemic sclerosis. Sci Rep. (2018) 8:11843. doi: 10.1038/s41598-018-29901-w

166. Wu X, Qiu W, Hu Z, Lian J, Liu Y, Zhu X, et al. An adiponectin receptor agonist reduces type 2 diabetic periodontitis. J Dent Res. (2019) 98:313-21. doi: $10.1177 / 0022034518818449$

167. Zhou Q, Xiang H, Li A, Lin W, Huang Z, Guo J, et al. Activating adiponectin signaling with exogenous adiporon reduces myelin lipid accumulation and suppresses macrophage recruitment after spinal cord injury. J Neurotrauma. (2019) 36:903-18. doi: 10.1089/neu.2018.5783

168. Malih S, Najafi R. AdipoRon: a possible drug for colorectal cancer prevention? Tumour Biol. (2015) 36:6673-5. doi: 10.1007/s13277-015-3911-3

169. Messaggio F, Mendonsa AM, Castellanos J, Nagathihalli NS, Gorden L, Merchant NB, et al. Adiponectin receptor agonists inhibit leptin induced pSTAT3 and in vivo pancreatic tumor growth. Oncotarget. (2017) 8:8537891. doi: 10.18632/oncotarget. 19905

170. Zhang Y, Zhao J, Li R, Lau WB, Yuan YX, Liang B, et al. AdipoRon, the first orally active adiponectin receptor activator, attenuates postischemic myocardial apoptosis through both AMPK-mediated and AMPKindependent signalings. Am J Physiol Endocrinol Metab. (2015) 309:E275-82. doi: 10.1152/ajpendo.00577.2014

171. Malih S, Saidijam M, Mansouri K, Pourjafar M, Tafakh MS, Talebzadeh F, et al. Promigratory and proangiogenic effects of AdipoRon on bone marrowderived mesenchymal stem cells: an in vitro study. Biotechnol Lett. (2017) 39:39-44. doi: 10.1007/s10529-016-2214-0

172. Nicolas S, Debayle D, Bechade C, Maroteaux L, Gay AS, Bayer P, et al. Adiporon, an adiponectin receptor agonist acts as an antidepressant and metabolic regulator in a mouse model of depression. Transl Psychiatry. (2018) 8:159. doi: 10.1038/s41398-018-0210-y

173. Sun F, Lei Y, You J, Li C, Sun L, Garza J, et al. Adiponectin modulates ventral tegmental area dopamine neuron activity and anxietyrelated behavior through AdipoR1. Mol Psychiatry. (2019) 24:126-44. doi: 10.1038/s41380-018-0102-9

174. Choi SR, Lim JH, Kim MY, Kim EN, Kim Y, Choi BS, et al. Adiponectin receptor agonist AdipoRon decreased ceramide, and lipotoxicity, and ameliorated diabetic nephropathy. Metabolism. (2018) 85:348-60. doi: 10.1016/j.metabol.2018.02.004

175. Kim Y, Lim JH, Kim MY, Kim EN, Yoon HE, Shin SJ, et al. The adiponectin receptor agonist AdipoRon ameliorates diabetic nephropathy in a model of type 2 diabetes. J Am Soc Nephrol. (2018) 29:1108-27. doi: 10.1681/ASN.2017060627
176. Hong K, Lee S, Li R, Yang Y, Tanner MA, Wu J, et al. Adiponectin receptor agonist, AdipoRon, causes vasorelaxation predominantly via a direct smooth muscle action. Microcirculation. (2016) 23:207-20. doi: 10.1111/micc.12266

177. Esfahani M, Shabab N, Saidijam M. AdipoRon may be benefit for atherosclerosis prevention. Iran J Basic Med Sci. (2017) 20:107-9. doi: 10.22038/ijbms.2017.8228

178. Fairaq A, Shawky NM, Osman I, Pichavaram P, Segar L. AdipoRon, an adiponectin receptor agonist, attenuates PDGF-induced VSMC proliferation through inhibition of mTOR signaling independent of AMPK: implications toward suppression of neointimal hyperplasia. Pharmacol Res. (2017) 119:289-302. doi: 10.1016/j.phrs.2017.02.016

179. Wang Y, Liang B, Lau WB, Du Y, Guo R, Yan Z, et al. Restoring diabetes-induced autophagic flux arrest in ischemic/reperfused heart by ADIPOR (adiponectin receptor) activation involves both AMPKdependent and AMPK-independent signaling. Autophagy. (2017) 13:185569. doi: 10.1080/15548627.2017.1358848

180. Narasimhan ML, Coca MA, Jin J, Yamauchi T, Ito Y, Kadowaki T, et al. Osmotin is a homolog of mammalian adiponectin and controls apoptosis in yeast through a homolog of mammalian adiponectin receptor. Mol Cell. (2005) 17:171-80. doi: 10.1016/j.molcel.2004.11.050

181. Miele M, Costantini S, Colonna G. Structural and functional similarities between osmotin from Nicotiana tabacum seeds and human adiponectin. PLoS ONE. (2011) 6:e16690. doi: 10.1371/annotation/69357261-7e31-40e0-96ff-13cdc783c768

182. Tang CH, Chiu YC, Tan TW, Yang RS, Fu WM. Adiponectin enhances IL-6 production in human synovial fibroblast via an AdipoR1 receptor, AMPK, p38, and NF-kappa B pathway. J Immunol. (2007) 179:5483-92. doi: 10.4049/jimmunol.179.8.5483

183. Liu J, Sui H, Zhao J, Wang Y. Osmotin protects H9c2 cells from simulated ischemia-reperfusion injury through AdipoR1/PI3K/AKT signaling pathway. Front Physiol. (2017) 8:611. doi: 10.3389/fphys.2017.00611

184. Takahashi Y, Watanabe R, Sato Y, Ozawa N, Kojima M, WatanabeKominato K, et al. Novel phytopeptide osmotin mimics preventive effects of adiponectin on vascular inflammation and atherosclerosis. Metabolism. (2018) 83:128-38. doi: 10.1016/j.metabol.2018.01.010

185. Ahmad A, Ali T, Kim MW, Khan A, Jo MH, Rehman SU, et al. Adiponectin homolog novel osmotin protects obesity/diabetes-induced NAFLD by upregulating AdipoRs/PPARalpha signaling in ob/ob and $\mathrm{db} / \mathrm{db}$ transgenic mouse models. Metabolism. (2019) 90:31-43. doi: 10.1016/j.metabol.2018.10.004

186. Jo MG, Kim MW, Jo MH, Bin Abid N, Kim MO. Adiponectin homolog osmotin, a potential anti-obesity compound, suppresses abdominal fat accumulation in C57BL/6 mice on high-fat diet and in 3T3-L1 adipocytes. Int J Obes (Lond). (2019). doi: 10.1038/s41366-019-0383-3. [Epub ahead of print].

187. Anil Kumar S, Hima Kumari P, Shravan Kumar G, Mohanalatha C, Kavi Kishor PB. Osmotin: a plant sentinel and a possible agonist of mammalian adiponectin. Front Plant Sci. (2015) 6:163. doi: 10.3389/fpls.2015.00163

188. Ali T, Yoon GH, Shah SA, Lee HY, Kim MO. Osmotin attenuates amyloid beta-induced memory impairment, tau phosphorylation and neurodegeneration in the mouse hippocampus. Sci Rep. (2015) 5:11708. doi: 10.1038/srep11708

189. Badshah H, Ali T, Kim MO. Osmotin attenuates LPS-induced neuroinflammation and memory impairments via the TLR4/NFkappaB signaling pathway. Sci Rep. (2016) 6:24493. doi: 10.1038/srep24493

190. Shah SA, Yoon GH, Chung SS, Abid MN, Kim TH, Lee HY, et al. Osmotin reduced amyloid beta (Abeta) burden by inhibiting SREBP2 expression in APP/PS1 mice. Mol Psychiatry. (2017) 22:323. doi: 10.1038/mp.2017.12

191. Shah SA, Yoon GH, Chung SS, Abid MN, Kim TH, Lee HY, et al. Novel osmotin inhibits SREBP2 via the AdipoR1/AMPK/SIRT1 pathway to improve Alzheimer's disease neuropathological deficits. Mol Psychiatry. (2017) 22:407-16. doi: 10.1038/mp.2016.23

192. Yoon G, Shah SA, Ali T, Kim MO. The adiponectin homolog osmotin enhances neurite outgrowth and synaptic complexity via AdipoR1/NgR1 signaling in Alzheimer's disease. Mol Neurobiol. (2018) 55:6673-86. doi: $10.1007 / \mathrm{s} 12035-017-0847-1$

193. Amin FU, Hoshiar AK, Do TD, Noh Y, Shah SA, Khan MS, et al. Osmotin-loaded magnetic nanoparticles with electromagnetic guidance 
for the treatment of Alzheimer's disease. Nanoscale. (2017) 9:10619-32. doi: 10.1039/C7NR00772H

194. Ma L, Zhang Z, Xue X, Wan Y, Ye B, Lin K. A potent peptide as adiponectin receptor 1 agonist to against fibrosis. J Enzyme Inhib Med Chem. (2017) 32:624-31. doi: 10.1080/14756366.2017.1284067

195. Kim S, Lee Y, Kim JW, Son YJ, Ma MJ, Um JH, et al. Discovery of a novel potent peptide agonist to adiponectin receptor 1. PLoS ONE. (2018) 13:e0199256. doi: 10.1371/journal.pone.0199256

196. Brown JE, Conner AC, Digby JE, Ward KL, Ramanjaneya M, Randeva HS, et al. Regulation of beta-cell viability and gene expression by distinct agonist fragments of adiponectin. Peptides. (2010) 31:944-9. doi: 10.1016/j.peptides.2010.02.004

197. Singh AK, Joharapurkar AA, Khan MP, Mishra JS, Singh N, Yadav M, et al. Orally active osteoanabolic agent GTDF binds to adiponectin receptors, with a preference for AdipoR1, induces adiponectin-associated signaling, and improves metabolic health in a rodent model of diabetes. Diabetes. (2014) 63:3530-44. doi: 10.2337/db13-1619

198. Sayeed M, Gautam S, Verma DP, Afshan T, Kumari T, Srivastava AK, et al. A collagen domain-derived short adiponectin peptide activates APPL1 and AMPK signaling pathways and improves glucose and fatty acid metabolisms. J Biol Chem. (2018) 293:13509-23. doi: 10.1074/jbc.RA118.001801

199. Tsuchida A, Yamauchi T, Ito Y, Hada Y, Maki T, Takekawa S, et al. Insulin/Foxol pathway regulates expression levels of adiponectin receptors and adiponectin sensitivity. J Biol Chem. (2004) 279:30817-22. doi: $10.1074 /$ jbc.M402367200

200. Mullen KL, Pritchard J, Ritchie I, Snook LA, Chabowski A, Bonen A, et al. Adiponectin resistance precedes the accumulation of skeletal muscle lipids and insulin resistance in high-fat-fed rats. Am J Physiol Regul Integr Comp Physiol. (2009) 296:R243-51. doi: 10.1152/ajpregu.90774.2008

201. Van Berendoncks AM, Garnier A, Beckers P, Hoymans VY, Possemiers N, Fortin D, et al. Exercise training reverses adiponectin resistance in skeletal muscle of patients with chronic heart failure. Heart. (2011) 97:1403-9. doi: 10.1136/hrt.2011.226373

202. Aouida M, Kim K, Shaikh AR, Pardo JM, Eppinger J, Yun DJ, et al. A Saccharomyces cerevisiae assay system to investigate ligand/AdipoR1 interactions that lead to cellular signaling. PLoS ONE. (2013) 8:e65454. doi: 10.1371/journal.pone.0065454

203. Sun Y, Zang Z, Zhong L, Wu M, Su Q, Gao X, et al. Identification of adiponectin receptor agonist utilizing a fluorescence polarization based high throughput assay. PLoS ONE. (2013) 8:e63354. doi: 10.1371/journal.pone.0063354

204. Tanabe H, Fujii Y, Okada-Iwabu M, Iwabu M, Nakamura Y, Hosaka T, et al. Crystal structures of the human adiponectin receptors. Nature. (2015) 520:312-6. doi: 10.1038/nature14301

205. Komaroff AL. The microbiome and risk for obesity and diabetes. JAMA. (2017) 317:355-6. doi: 10.1001/jama.2016.20099

206. Vrieze A, Van Nood E, Holleman F, Salojarvi J, Kootte RS, Bartelsman JF, et al. Transfer of intestinal microbiota from lean donors increases insulin sensitivity in individuals with metabolic syndrome. Gastroenterology. (2012) 143:913-6 e917. doi: 10.1053/j.gastro.2012.06.031

207. Su X, Yan H, Huang Y, Yun H, Zeng B, Wang E, et al. Expression of FABP4, adipsin and adiponectin in Paneth cells is modulated by gut Lactobacillus. Sci Rep. (2015) 5:18588. doi: 10.1038/srep18588

208. Zhang Y, Ma C, Zhao J, Xu H, Hou Q, Zhang H. Lactobacillus casei Zhang and vitamin $\mathrm{K} 2$ prevent intestinal tumorigenesis in mice via adiponectinelevated different signaling pathways. Oncotarget. (2017) 8:24719-27. doi: 10.18632/oncotarget.15791

209. Enright EF, Griffin BT, Gahan CGM, Joyce SA. Microbiome-mediated bile acid modification: role in intestinal drug absorption and metabolism. Pharmacol Res. (2018) 133:170-86. doi: 10.1016/j.phrs.2018.04.009
210. Dib J, Thomas A, Delahaut P, Fichant E, Schanzer W, Thevis M. Identification and characterization of in vitro and in vivo generated metabolites of the adiponectin receptor agonists AdipoRon and 112254. J Pharm Biomed Anal. (2016) 125:68-76. doi: 10.1016/j.jpba.2016. 03.027

211. Zimmermann M, Zimmermann-Kogadeeva M, Wegmann R, Goodman AL. Separating host and microbiome contributions to drug pharmacokinetics and toxicity. Science. (2019) 363:eaat9931. doi: 10.1126/science. aat9931

212. Ajit C, Suvannasankha A, Zaeri N, Munoz SJ. Terbinafineassociated hepatotoxicity. Am J Med Sci. (2003) 325:292-5. doi: 10.1097/00000441-200305000-00008

213. Barnette DA, Davis MA, Dang NL, Pidugu AS, Hughes T, Swamidass SJ, et al. Lamisil (terbinafine) toxicity: determining pathways to bioactivation through computational and experimental approaches. Biochem Pharmacol. (2018) 156:10-21. doi: 10.1016/j.bcp.2018.07.043

214. Davis MA, Barnette DA, Flynn NR, Pidugu AS, Swamidass SJ, Boysen G, et al. CYP2C19 and 3A4 dominate metabolic clearance and bioactivation of terbinafine based on computational and experimental approaches. Chem Res Toxicol. (2019) 32:1151-64. doi: 10.1021/acs.chemrestox. $9 \mathrm{~b} 00006$

215. Lampe JW, Navarro SL, Hullar MA, Shojaie A. Inter-individual differences in response to dietary intervention: integrating omics platforms towards personalised dietary recommendations. Proc Nutr Soc. (2013) 72:207-18. doi: $10.1017 /$ S0029665113000025

216. Barnea M, Chapnik N, Genzer Y, Froy O. The circadian clock machinery controls adiponectin expression. Mol Cell Endocrinol. (2015) 399:284-7. doi: 10.1016/j.mce.2014.10.018

217. Smits SA, Marcobal A, Higginbottom S, Sonnenburg JL, Kashyap PC. Individualized responses of gut microbiota to dietary intervention modeled in humanized mice. mSystems. (2016) 1. doi: 10.1128/mSystems. 00098-16

218. Vaccaro O, Lucisano G, Masulli M, Bonora E, Del Prato S, Rivellese AA, et al. Cardiovascular effects of pioglitazone or sulphonylureas according to pretreatment risk: moving towards personalized care. J Clin Endocrinol Metab. (2019) 104:3296-302. doi: 10.1210/jc.201900361

219. Li-Pook-Than J, Snyder M. iPOP goes the world: integrated personalized omics profiling and the road toward improved health care. Chem Biol. (2013) 20:660-6. doi: 10.1016/j.chembiol.2013.05.001

220. Piening BD, Zhou W, Contrepois K, Rost H, Gu Urban GJ, Mishra $\mathrm{T}$, et al. Integrative personal omics profiles during periods of weight gain and loss. Cell Syst. (2018) 6:157-70 e158. doi: 10.1016/j.cels.2017. 12.013

221. Schussler-Fiorenza Rose SM, Contrepois K, Moneghetti KJ, Zhou W, Mishra T, Mataraso S, et al. A longitudinal big data approach for precision health. Nat Med. (2019) 25:792-804. doi: 10.1038/s41591-019-0414-6

Conflict of Interest: YL was employed by iCarbonX.

The remaining authors declare that the research was conducted in the absence of any commercial or financial relationships that could be construed as a potential conflict of interest.

Copyright () $2019 \mathrm{Liu}, \mathrm{Vu}$ and Sweeney. This is an open-access article distributed under the terms of the Creative Commons Attribution License (CC BY). The use, distribution or reproduction in other forums is permitted, provided the original author(s) and the copyright owner(s) are credited and that the original publication in this journal is cited, in accordance with accepted academic practice. No use, distribution or reproduction is permitted which does not comply with these terms. 